\title{
Spending from regulated retirement drawdowns: the role of implied endorsement
}

\author{
Jennifer Alonso-García* Hazel Bateman ${ }^{\dagger} \quad$ Johan Bonekamp $^{\ddagger} \quad$ Ralph Stevens ${ }^{\S}$
}

October 17, 2019

This project has received funding from the ARC Centre of Excellence in Population Ageing Research (grant CE110001029 and grant CE17010005) and ARC Linkage Grant 'Mandatory prefunded retirement income schemes: Best policy and practice' (grant LP140100104). We would like to thank the staff at the Institute for Choice, University of South Australia, and CentERdata for generous assistance with the development and implementation of the online surveys. Particular thanks to Jordan Louviere for sharing his expertise in survey design and Karen Cong for expert programming. Earlier drafts of this paper were circulated under the title: "Decumulation of wealth during retirement: what is the effect of Implied Endorsement" and "Retirement drawdown defaults: the role of implied endorsement". We thank Eduard Ponds, Arthur van Soest, Lisette Swart and Nicolas Drouhin for feedback, and attendees at the following conferences for comments and discussion: Netspar Pension Day (Utrecht, October 2017), CPB academic seminar (The Hague, March 2018), 16th Annual Conference on Pension, Insurance and Savings (Lisbon, April 2018), Boulder Summer Conference on Consumer Financial Decision Making (Boulder, May 2018). The authors are responsible for any errors.

*Email: j.alonso-garcia@rug.nl; Department of Economics, Econometrics and Finance, University of Groningen, the Netherlands; Email: jennifer.alonso.garcia@ulb.ac.be; Faculté des Sciences, Université Libre de Bruxelles, Belgium; ARC Centre of Excellence in Population Ageing Research (CEPAR), UNSW Sydney, Australia.

†Email: h.bateman@unsw.edu.au; ARC Centre of Excellence in Population Ageing Research (CEPAR), UNSW Sydney, Australia; School of Risk and Actuarial Studies, UNSW Sydney, Australia; Network for Studies on Pensions, Aging and Retirement (Netspar), the Netherlands.

${ }_{\ddagger}^{\ddagger}$ Email: J.L.M.Bonekamp@uvt.nl; Department of Econometrics and Operations Research, Tilburg University, the Netherlands; Network for Studies on Pensions, Aging and Retirement (Netspar), the Netherlands.

§Email: ralphste@hotmail.com; ARC Centre of Excellence in Population Ageing Research (CEPAR), UNSW Sydney, Australia; Network for Studies on Pensions, Aging and Retirement (Netspar), the Netherlands. 


\begin{abstract}
We fielded an online survey in the Netherlands and Australia to explore the influence of an implied endorsement nudge, conveyed by a government regulated drawdown from pension wealth, on spending patterns in retirement. The implied endorsement nudge was effective. It influenced the preferred retirement spending patterns of around $30 \%$ of survey participants, particularly those with fewer financial resources and low pension capability. Australian participants were more likely to follow the nudge where it was framed as implicit government advice while the Dutch were more likely to respond to a suggestion that the nudge was a recommendation from peers. Our results provide support for a regulated drawdown rule as part of a strategy to guide spending patterns in retirement.
\end{abstract}

JEL: D14, D90, J14, J26

Keywords: decumulation policy, regulated drawdowns, implied endorsement, peer effects 


\section{Introduction}

The increasing emphasis on defined contributions (DC) pensions arrangements is changing the retirement benefit landscape. Retirees are less likely to be in receipt of lifelong pensions or annuities, and more likely to be required to make decisions about retirement benefit products and drawdowns from retirement wealth (OECD, 2015).

Deciding how much to spend and save in retirement is difficult for most people and recent empirical studies for different countries show that many retirees hold onto their assets or even keep on saving well into old age; see Dynan et al. (2004) and Love et al. (2009) for the United States, Van Ooijen et al. (2015) for the Netherlands, and Asher et al. (2017) for Australia. The policy toolkit to assist with retirement benefit and drawdown decisions includes mandates (e.g., requiring full annuitization), economic incentives (e.g., providing concessions such as lower tax rates for the take-up of certain benefits or drawdown patterns) and nudges to alter or guide behaviour - see Thaler and Sunstein (2008), Benartzi et al. (2017) and Chetty et al. (2014). ${ }^{1}$ Nudges are of many types and their number and variety are constantly growing (Sunstein, 2014). The most important for policy purposes can be classified into four different groups: 1) simplification and framing of information; 2) changes to default rules; 3) social norm comparisons; and 4) changes to the physical environment (Lehner et al., 2016).

In this paper we use an online survey comprising hypothetical choice tasks and collection of data on personal characteristics, preferences, financial competence and personality traits to investigate the role that nudges may play in guiding decisions to spend from drawdowns of pension wealth. We study several types of nudges which could be used to guide spending in retirement. First, we examine whether and the extent to which government regulated drawdowns from pension wealth are conveyed as implied endorsement for spending patterns in retirement. We then examine the importance of two alternative prompts for this implied endorsement communicated as 1) implicit advice from the government ("government knows best"), and 2) a social norm comparison or peer effect ("what most people do"). ${ }^{2}$

Our experimental setup uses two vignettes to present short descriptions of hypothetical retiree households with given patterns of wealth and income, given expected future health status and two different policies for the drawdown of pension wealth. In one vignette the hypothetical retiree household has full flexibility of drawdown from pension wealth while in the other the household is required to follow a government prescribed drawdown from their pension wealth. Survey participants from the Netherlands and Australia are asked to advise the hypothetical retiree household on a spending trajectory and to rank the motives for saving consistent with the advice that is given. The set of motives is drawn from economic theory and

\footnotetext{
${ }^{1}$ Barberis (2018) provides a comprehensive summary of policy tools that have been successful in guiding people to make better retirement decisions and increase their savings.

${ }^{2}$ Dinner et al. (2011), in a study of the effect of implied endorsement in the choice of light bulbs, labelled "government" implied endorsement as "direct" implied endorsement and the "peer effect" as "external" implied endorsement.
} 
the psychology literature and includes implicit advice from government and a social norm comparison.

The Netherlands and Australia are ideal settings for our study. Both countries are consistently ranked in the top four pension systems internationally by the Melbourne Mercer Global Pension Index (Mercer, 2018). They have a similar structure comprising a publicly funded state pension and a funded income replacement pillar supplemented by voluntary saving, but an important difference in the decumulation phase. Dutch retirees are required to convert the retirement savings from the income replacement pillar into lifetime annuities while Australian retirees have considerable flexibility, with the discretion to take a lump sum, a phased withdrawal product (known in Australia as an account-based pension) or a term or lifetime annuity. Most Australian retirees take account-based pensions which are associated with tax concessions for minimum annual withdrawals from pension wealth (APRA, 2017).

The experimental design allows us to answer a number of important questions about the impact of government regulated drawdowns from pension wealth on spending behaviour in retirement and the role of implied endorsement, implicit advice and social norm comparisons in guiding spending patterns. Moreover, the collection of information in our online survey on demographics, preferences, psychological traits, and financial competence, as well as country of residence enables us to identify the characteristics of those who are influenced by the nudges we implement.

To date the most common nudge examined in the pensions literature is the default. The effectiveness of defaults has been shown in the accumulation of retirement savings where choices include whether to participate, which fund or plan to join, how much to contribute and which investment option to take - see Madrian and Shea (2001), Choi et al. (2002), Choi et al. (2004) and Choi et al. (2005) for 401k plans in the US, Fry et al. (2007), Gerrans and Clark-Murphy (2004), Bateman et al. (2014) and Dobrescu et al. (2018) for Australian mandatory retirement saving (superannuation) arrangements and Hedesstrom et al. (2004) for the Swedish premium pension (SPP) scheme. In the retirement decumulation phase a series of papers have found that retiring plan members tend to stick to the default benefit option offered by their plan. This explains the predominance of annuities in the Swiss system, where the benefit default is more often a life annuity than a lump sum (Bütler and Teppa, 2007) and vice versa for 401(k) plans in the US (Benartzi et al., 2011) where a lump sum distribution is the more common default.

In this paper we aim to better understand spending (and saving) trajectories in retirement. While regulated drawdowns compel regular withdrawal of pension wealth there is no requirement that these withdrawals be spent. However, we suggest that the regulated nature of the drawdowns could provide strong guidance via implied endorsement for how much to spend, and retirement spending trajectories may follow the regulated drawdowns as per the stickiness of defaults. In this context we investigate whether a government regulated drawdown from pension wealth conveys implied endorsement for spending trajectories. Previous studies have examined implied endorsement in a variety of contexts - such as for food subsidy schemes (Griffith et al., 2018) and cash transfers for education (Benhassine et al., 2015). To our knowledge, there has been no research on the extent to which retirees use regulated 
drawdowns of their pension wealth as guidance for their spending trajectories. ${ }^{3}$

By comparing retirement spending trajectories in vignettes without and then with a regulated drawdown, our first key finding is that a large majority of survey participants change their spending pattern to match the regulated drawdown. Importantly, vulnerable groups - to whom such policies are targeted - such as those with low financial resources and low pension capability, are more likely to be influenced by the implied endorsement. In drawing this conclusion we emphasise the role that regulated drawdowns could play as a tool to influence spending in retirement but we fall shot of advocating whether this spending is optimal or not.

Second, we identify avenues through which implied endorsement operates by investigating the impact of two prompts relating drawdowns and spending - one in a social norm context and the other suggesting that the regulated drawdown is in fact implicit government advice. The use of social norm comparisons has been successful in influencing behaviour across a number of domains including tax compliance, energy use and recycling where the strategy to nudge or influence behaviour is to highlight what "most people do". For example, in the case of tax compliance, people could be told "most people pay their taxes on time" (Sunstein, 2013). In a large-scale field experiment designed to learn about the factors that influence the timely payment of taxes in the United Kingdom, Hallsworth et al. (2017) found that social norm comparisons were more effective than public good messaging (i.e., reminding people that paying taxes funds health, roads and schools). Evidence on the role of social norm comparisons (or peer effects) to facilitate complex life cycle spending and saving decisions is mixed. Duflo and Saez $(2002,2003)$ in two studies on the retirement saving behaviour of university librarians found strong peer effects in employee pension plan decisions, and Brown et al. (2008) find similar effects for stock market participation. However, Beshears et al. (2015) found the opposite effect following the presentation of peer information about retirement savings.

In this study we are interested in the strength of two alternative prompts for implied endorsement - first, that the household's spending follows to the withdrawal amounts as suggested by the government as "government knows best", which we interpret as "implicit government advice" and second, as "that is what most people do", which we interpret as a "peer effect". We find that the Australian participants are more influenced by "implicit government advice" and the Dutch by "peer effects". As expected, the peer effect is reduced for those with less opportunity to participate in a social network but enhanced for those who are risk averse.

The remainder of this paper is organized as follows. Section 2 describes the online experimental survey including the vignette task used to elicit choice of spending trajectory. In Section 3 we describe the data and report descriptive statistics. Section 4 discusses the estimation results and reports robustness tests, while in Section 5 we discuss our findings and conclude.

\footnotetext{
${ }^{3}$ In Australia's superannuation arrangements most retirees take their retirement benefits as phased withdrawal products (known in Australia as account-based pensions) (APRA, 2017). However, the extent to which they stick to the regulated age-based minimum drawdown requirements is unclear.
} 


\section{Survey design}

We designed a choice task in an online survey to elicit whether a government regulated retirement drawdown influenced choice of spending trajectories in retirement. In the choice task participants were asked to choose a spending pattern out of five alternatives for their retirement years. The experimental setting also allowed us to elicit the motivation for this choice, specifically whether they followed the regulated drawdown because they considered the prescribed drawdown rate to be implicit advice from government as to how much to spend, or they interpreted the regulated drawdown rate as advice from peers. Alternatively a further group may independently decide on their retirement spending pattern.

We used vignettes to present the choice sets (see Louviere et al., 2000). The vignettes comprised a short description of a hypothetical household with information about their retirement income and wealth, home ownership and expected future health status. For this study, we focus on two (of eight) vignettes presented to survey participants. A flexible drawdown vignette which places no restriction on the amount the hypothetical household can draw down from their retirement wealth and a regulated drawdown vignette in which the hypothetical household is required to draw down an amount prescribed by government. The choice task asks participants to choose a spending trajectory, for each of the flexible drawdown vignette and regulated drawdown vignette, and then to rank in order of importance a list of five possible saving/spending motives for this choice. We are particularly interested in whether participants change their preferred spending trajectory between the flexible drawdown vignette and the regulated drawdown vignette. Where the chosen spending trajectory closely follows the regulated drawdown pattern we conclude that the regulated drawdown requirement acts as implied endorsement.

The online survey was fielded in the Netherlands (in Dutch) and Australia (in English) which allowed us to identify any country and/or institutional effects for implied endorsement and its motivators. ${ }^{4}$

There are several advantages with our approach of using vignettes to frame the choice task. First, we can control for country specific factors by asking survey participants to abstract from their own pension arrangements and focus on the circumstances of the vignette household. For example, in the Netherlands the state pension is universal, whereas in Australia it is means-tested. ${ }^{5}$ Furthermore, we can control various otherwise unobserved circumstances (e.g. home ownership, marital status or health status). Additional advantages of the online survey include that we can ask participants to make choices in hypothetical policy settings (e.g., we ask the Dutch participants to choose a spending trajectory in the context of a regulated drawdown from pension wealth, whereas Dutch retirees are likely only familiar with lifetime pensions). Moreover, we can collect a lot of additional information about participants (e.g. in this survey we ask questions about personality traits, risk pref-

\footnotetext{
${ }^{4} \mathrm{An}$ interactive link to the English version of the survey is available at http://survey.us.confirmit.com/wix/6/p3081554696.aspx. Screen shots of the full survey are set out in the supplementary material.

${ }^{5}$ An overview of the Dutch and Australian pension schemes is provided in Appendix A.
} 
erences, demographics, personal characteristics and financial competence). Finally, and most important for this study, we can ask participants for the motivation for their choices.

\section{$2.1 \quad$ Survey overview}

The online survey comprised screening questions followed by four modules completed by those who qualified - see Figure 1. Individuals were screened on gender (50/50), age and workforce status. Only individuals aged 50-64 and not yet retired were invited to participate. Individuals in this age group are more likely to have thought about retirement and by restricting participation to those not retired we reduced the likelihood that the elicited preferences were confounded by real-life choices. Eligible participants were then asked about their gross household income and placed in one of four "income" treatments. ${ }^{6}$ This was done to address possible alienation with the choice task by allocating participants vignette versions where the financial information most closely matched their own circumstances. ${ }^{7}$

Following screening, participants proceeded to the four modules. The first module was the choice task, described in more detail in section 2.2. The second comprised questions on retirement planning and planning horizon (Fisher and Montalto, 2011), risk attitude (Dohmen et al., 2011) and personality traits elicited using the ten-item personality inventory (TIPI) (Gosling et al., 2003). The third module asked questions on financial competence, including financial literacy (Lusardi and Mitchell, 2011), numeracy (Lipkus et al., 2001) and pension knowledge (Agnew et al., 2013). The fourth module concluded the survey with questions on demographics and personal characteristics. The median time for completion of the survey was 30 minutes for Australian participants and 31 minutes for Dutch participants.

\subsection{Choice Task}

The complete choice task comprised eight vignettes. each vignette had a standard format describing a hypothetical household of two individuals aged 65 who had just retired and own the house they live in. Available wealth, lifelong income and health status of each of the household members could differ between vignettes, and wealth and income were aligned with one of the four household income groups. The base vignette is shown in Figure B.1 (Appendix B).

For each vignette household there were two tasks. First (identified as Part A in the choice task), participants were asked to advise a retirement spending trajectory

\footnotetext{
${ }^{6}$ For the Dutch participants, information on age, work-status and gross household were already available as background information so the additional information was collected only for Australian participants.

${ }^{7}$ There might still be considerable heterogeneity between personal savings of participants within an "income" treatment. As retirees are not allowed to participate, we have already excluded a group who might supplement a low income using their savings. Furthermore, preliminary analysis suggests that a minor mismatch between a respondent (self-reported) income group and the "income" treatment (s)he received, does not significantly influences responses to the choice task.
} 
for the hypothetical household out of five alternatives (based on their own preferences). These five alternatives were the same, per participant, between vignettes. The spending trajectories were chosen so that the participant could always advise a spending trajectory such that wealth of the hypothetical household would increase, decrease or remained constant. To help the participant with this decision, information on remaining wealth of the hypothetical household at the age of $65,75,85$, and 95 was presented for each spending trajectory. Participants were informed that the hypothetical household could not acquire debt, so that for spending patterns that depleted wealth, spending was (automatically) adjusted to income from the drawdown. Second (identified as Part B in the choice task), participants were presented with five explanations (or motives) to justify their chosen spending (and saving) pattern and were asked to rank their importance using two rounds of best/worst elicitation (see Figure B.3, Appendix B for a representative screenshot). Per participant, the five motives were drawn from a full list of ten, and could vary between vignettes.

In reality the regular income and wealth available to retirees from their retirement saving (through pension and superannuation) can differ depending on countryspecific pension arrangements. For example, policy design in the Netherlands provide life annuities, but no access to pension wealth or flexibility of drawdown from that wealth, while in Australia policy design provides access to pension wealth and flexible drawdown from that wealth, but no requirements for regular annuity income. In the full choice task participants were presented vignettes with four different pension policy settings (see vignettes 1-4 in Figure 1). However, for this study of implied endorsement we consider just two: 1) a pension policy design which allowed for complete flexibility of drawdown from retirement wealth, which we refer to as the flexible drawdown vignette; and 2) a pension policy design under which households are required to follow a government prescribed drawdown from their retirement wealth referred to as regulated drawdown vignette, which is our implied endorsement nudge. The complete set of vignettes also included four vignettes that differed by the health states of the household members (see vignettes 5-8 in Figure 1). However, for this study we kept health status constant - that is, both members of the household "are in good health and expect to stay so until they reach the age of 70 ". ${ }^{8}$

\subsubsection{Flexible drawdown vignette}

The first three vignettes (as illustrated in Figure 1) are inspired by the real-life pension systems in Australia and the Netherlands. Vignette 1 represents the Dutch pension system which is characterized by full annuitization of pension accruals (and low liquidity), while vignette 2 represents the Australian pension system which is characterized by high flexibility and high liquidity of pension wealth. Rather than annuitizing their pension wealth, Australians generally supplement their meanstested statutory pension through a tax-preferred account-based pension. However, for this vignette we assume complete flexibility of drawdown. We will use the re-

\footnotetext{
${ }^{8}$ The full set of vignettes, except for the regulated drawdown vignette, are analysed in a companion paper by Alonso-García et al. (2018).
} 
Figure 1: Simplified overview of the different components within the survey.

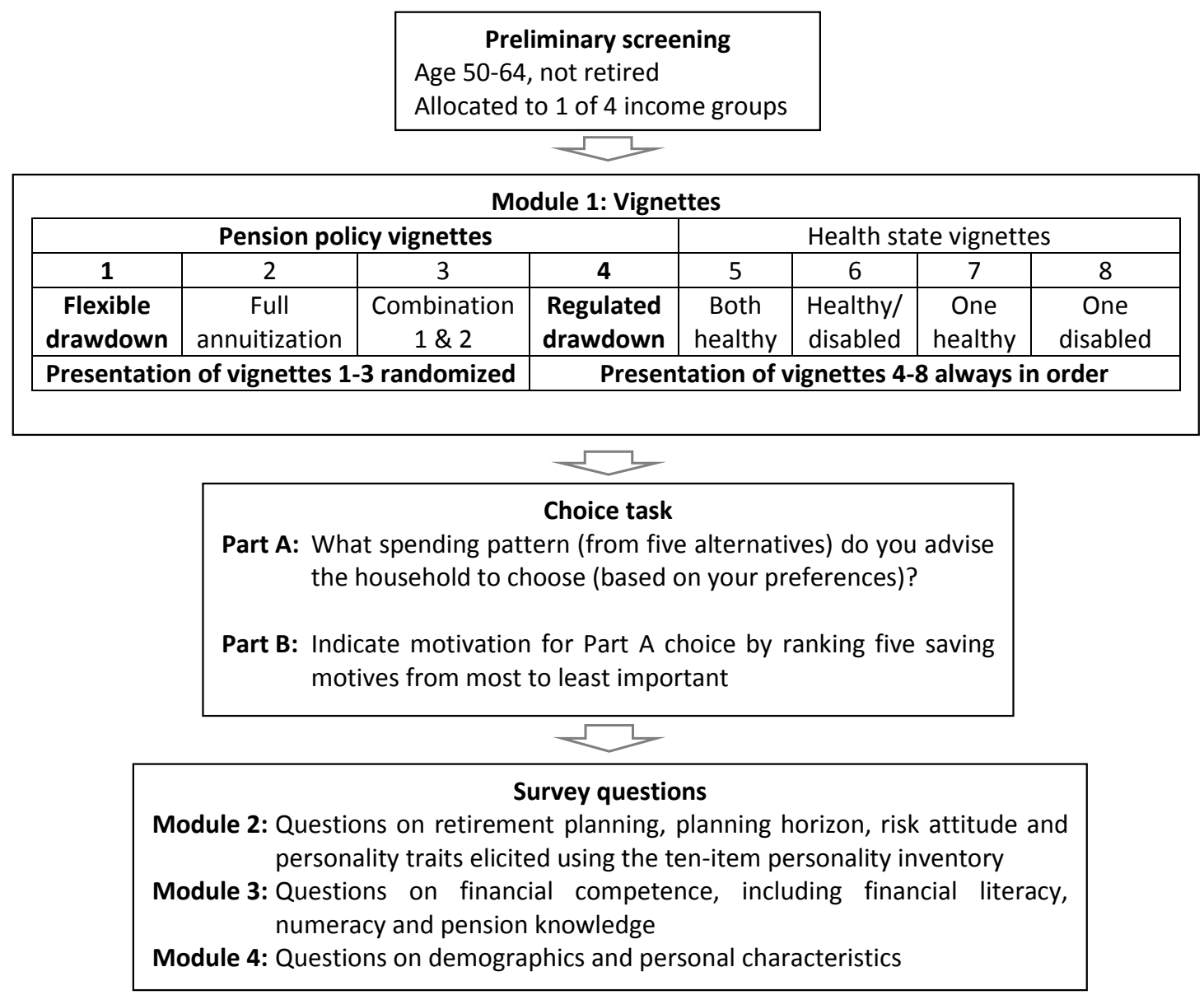

sponses to this stylized Australian vignette in this study (see Figure 1). We refer to this as the flexible drawdown vignette. Vignette 3 can be considered a mix between the Australian and Dutch pension system. That is, half of the pension wealth is annuitized. The order in which participants view the first three vignettes is randomized.

Per vignette, the participant is first (Part A) asked to advise a spending trajectory for the hypothetical household from five alternatives, based on their own preferences, and then (Part B) to rank five motives on the importance that accompany this spending decision using two rounds of best/worst. These five saving motives do not differ between the first three vignettes. In our study we are only interested in vignette 2 , the flexible drawdown vignette, although as discussed, this may be presented first, second or third.

For the first three vignettes (which include the flexible drawdown vignette) the five saving motives to be ranked are drawn from a list of ten. These ten are the result of a pre-test (using best/worst scaling) to identify the most and least important saving motives for people approaching or in retirement from an exhaustive list of 19 drawn from economic theory and the behavioural economics and psychology literature. ${ }^{9}$

\footnotetext{
${ }^{9}$ For more details on saving motives pre-test, see the appendix in Alonso-García et al. (2018).
} 
The ten saving motives arising from the pre-test are listed in Table 1. For the flexible drawdown vignette five saving motives are randomly selected, subject to three from the six "economic" inspired motives and two from the four "psychological" inspired motives.

It is possible for each vignette (including the flexible drawdown vignette) to derive the imputed ranking of each motive. The "best" ("worst") motive in the first round is labeled 1 (5), the second-best and second-worst motive are labeled 2, respectively 4 and the remaining motive is labeled 3 . The top 3 participant-specific motives labeled (1), (2) and (3) - for the flexible drawdown vignette will be used in Part B of the regulated drawdown vignette.

\subsubsection{Regulated drawdown vignette}

Vignette 4 is the regulated drawdown vignette. The text in this vignette coincides with the flexible drawdown vignette. The hypothetical household has, per participant, the same wealth and income and also the same five alternative spending plans. However, under the regulated drawdown vignette the hypothetical household must take up the minimum government regulated drawdown. In the experimental set-up the hypothetical household is obliged to withdraw a fixed amount of wealth each year equal to five percent of initial wealth at the age of retirement.

The wording of the regulated drawdown vignette differs from the flexible drawdown vignette by the following sentence placed in bold before the Part A Choice task: "Government regulations require that they withdraw a part of their wealth each year to supplement their income. This corresponds to $<<$ income category dependent amount $>>$. The household is not obliged to (fully) spend this supplementary income." (see the bold text in the illustrative screenshot shown in Figure B.4, Appendix B). This amount is the regulated drawdown set by the government, which we interpret as an "implied endorsement".

Minimum withdrawal rates are used in a number of countries including the United States (Internal Revenue Service, 2017), Canada (Canada Revenue Agency, 2017) and Australia (MoneySmart, 2016). For example, in Australia, retirees who follow age-based minimum withdrawals from their pension accounts ranging from $4 \%$ of the account balance at ages 60-64 to 14\% for individuals aged 95 and older receive tax concessions (MoneySmart, 2016). However, this minimum withdrawal requirement is not a minimum spending requirement. The minimum withdrawals can be spent or used to increase savings in non-pension accounts. We capture this feature in the regulated drawdown vignette by explicitly stating that the hypothetical household is not forced to consume all this (additional) income, as shown in Figure B.4 (Appendix B).

Since we are also interested in the strength of two alternative prompts for implied endorsement - one framing the change in the household spending patterns as "government knows best", which we interpret as "implicit government advice" and another framing the drawdown behaviour as "that is what most people do", which we interpret as a "peer effect" - we supplement the short list of ten saving motives with 
two additional motives as possible prompts for implied endorsement. The first is written as "The household wants to stick to the withdrawal amounts as suggested by the government as government knows best." and is designed to capture implicit advice from the government. The second is written as "The household wants to stick to the withdrawal amounts as suggested by the government as that is what most people do." is a social norms comparison designed to capture a peer effect. These additional saving motives as used in the regulated drawdown vignette can be found in the bottom two rows of Table 1.

Again, the participant is asked to advise a spending pattern out of five alternatives for the hypothetical household, based on their own preferences. Compared to the flexible drawdown vignette, we now gently push the participant to advise a spending plan that leads to less savings (i.e. consume more). However, the participant is not required to change the preferred spending plan. If the participant does change the advised spending plan, we see this as evidence for the effectiveness of our nudge. Next, the participant is asked to rank five motives on the importance that accompanies this spending decision using two rounds of best/worst. Here, the list of five saving motives for the regulated drawdown vignette consists of the earlier derived top three motives from the flexible drawdown vignette supplemented by the two additional motives (government advice and peer effect) in a random order.

Note that the regulated drawdown is always presented fourth, but the flexible drawdown is randomly assigned for presentation as first, second or third. Hence, the flexible drawdown and regulated drawdown may or may not be presented consecutively. If the two implied endorsement prompts are unimportant for the preferred spending plan by the participant, we would expect them to be ranked 4 and 5 .

\section{$3 \quad$ Data and descriptive statistics}

Our survey was fielded in the Netherlands and Australia. In Australia just over 1,000 individuals were recruited by the web panel provider 'TEG rewards' and received AU $\$ 4$ for completion of the survey. In the Netherlands we used of the wellestablished household panels LISS and DHS which are administered through Tilburg University. Participants complete surveys on a variety of topics on a regular basis and receive compensation for doing so. Almost 1,800 individuals participated in this survey. ${ }^{10}$

Following adjustment for Dutch participants who failed to satisfy screening criteria and those for whom information on relevant variables was missing our analysis sample comprised 2,420 participants - 1,437 Dutch and 983 Australians.

The key variables collected in the survey are defined in Table 2. Table 3 reports descriptive statistics for the dependent variables (top panel) and control variables (bottom panel).

\footnotetext{
${ }^{10}$ Overall, 2,485 panel members received an invitation to participate. Before the experiment was fielded, a response rate of around $73 \%$ was expected.
} 
Table 1: Saving motives used in the flexible and regulated drawdown vignettes

\begin{tabular}{|c|c|}
\hline Savings motive & Text in vignette \\
\hline \multicolumn{2}{|l|}{ Economic } \\
\hline precautionary & $\begin{array}{l}\text { wants to ensure that they will be able to finance any unforeseen } \\
\text { expenditures other than health and aged care expenditures }\end{array}$ \\
\hline precautionary health & $\begin{array}{l}\text { wants to ensure that they will be able to finance unforeseen health } \\
\text { and aged care expenditures }\end{array}$ \\
\hline life-span risk & wants to ensure that they will not outlive their wealth \\
\hline intended bequest & $\begin{array}{l}\text { wants to ensure that they will be able to leave a bequest to their } \\
\text { dependants or estate }\end{array}$ \\
\hline liquidity & wants to ensure that they have enough cash on hand at any time \\
\hline intra-household bequest & $\begin{array}{l}\text { wants to ensure that if they die, their partner is able to maintain } \\
\text { his/her standard of living }\end{array}$ \\
\hline \multicolumn{2}{|l|}{ Psychological } \\
\hline autonomy & wants to ensure that they remain financially independent \\
\hline security & $\begin{array}{l}\text { wants to ensure that they have enough money to have peace of } \\
\text { mind }\end{array}$ \\
\hline self-gratification & $\begin{array}{l}\text { wants to ensure that they are able to enjoy life now as well as } \\
\text { later }\end{array}$ \\
\hline political risk & $\begin{array}{l}\text { wants to ensure that they are protected against a change in the } \\
\text { superannuation / pension rules }\end{array}$ \\
\hline $\begin{array}{l}\text { Implied Endorsement } \\
\text { government advice }\end{array}$ & $\begin{array}{l}\text { (included in the regulated drawdown vignette) } \\
\text { wants to stick to the withdrawal amounts as suggested by the } \\
\text { government as government knows best. }\end{array}$ \\
\hline peer effect & $\begin{array}{l}\text { wants to stick to the withdrawal amounts as suggested by the } \\
\text { government as that is what most people do. }\end{array}$ \\
\hline
\end{tabular}

\subsection{Dependent variables}

To test whether the government regulated drawdown acts as implied endorsement for the amount of spending in retirement, we construct the variable changed advised spending pattern, that equals one if the participant changed their advised spending pattern in the regulated drawdown vignette from the flexible drawdown vignette, and zero otherwise. In the Australian sample over 30\% of participants changed their advised spending pattern compared to just under 30\% in the Dutch sample (see top panel of Table 3). This difference between Australia and the Netherlands is minor but significant with a $p$-value of $2.6 \%$.

Under our experimental design the implicit advice for spending and saving communicated by the regulated drawdown could have an effect either because it is interpreted as "government knows best" (implicit government advice) or because it provides information on "what most people do" (a peer effect), or alternatively, spending may be motived by other factors. Therefore, we construct two variables that capture the importance of these implied endorsement prompts. Since the menu of spending and saving motives for the regulated drawdown vignette included (for a given participant) the two implied endorsement saving motives together with the top three saving motives from the flexible drawdown vignette, an intuitive way is to model their importance as follows:

- First, the variable implied endorsement prompts equals one if either the gov- 
Table 2: Description of the relevant variables

\begin{tabular}{ll}
\hline \hline Covariate (indicator) & Explanation \\
\hline $\begin{array}{l}\text { Country of residence } \\
\text { Australia }\end{array}$ & 1 if participant took part in the Australian questionnaire, 0 otherwise \\
$\begin{array}{l}\text { Financial resources } \\
\text { Household income (Q3 and Q4) }\end{array}$ & $\begin{array}{l}1 \text { if participant belongs to the upper quartiles of (current) gross household income, } \\
0 \text { otherwise } \\
1 \text { if participant owns (potentially with a mortgage) the house (s)he lives in, } 0 \\
\text { otherwise }\end{array}$ \\
$\begin{array}{l}\text { Fomeowner } \\
\text { Time horizon: more than } 5 \text { years from now }\end{array}$ & $\begin{array}{l}1 \text { if participant answered a time horizon of at least five years to the question } \\
\text { "People use different time-horizons when they decide which part of their income } \\
\text { to spend, and which part to save. Which of the time-horizons mentioned below } \\
\text { is in your household most important with regard to planning expenditures and } \\
\text { savings for you?", 0 otherwise }\end{array}$
\end{tabular}

Pension capability

Objectively measured

Self-assessed capability ${ }^{a}$

\section{Social network}

Age: 60-64

Religious / Member of a church community

\section{Additional control variables}

Gender = female

Marital status $=$ partner

Employed $^{b}$

Children living at home

Age: 50-54

Age: 55-59

Born in the country in which they currently live

Covariate (standardized)
personality: TIPI extraversion
personality: TIPI neuroticism

Personality

personality: TIPI conscientiousness

risk aversion
1 if participant made fewer mistakes than the average of the population in financial literacy (Lusardi and Mitchell, 2011), numeracy (Lipkus et al., 2001), and pension system knowledge questions (Bateman et al., 2018), 0 otherwise 1 if participant is more confident in his/her own pension-related capability than the average of the population, 0 otherwise

1 if participant is in the 60 to 64 age group, 0 otherwise

1 if participant considers himself / herself as member of a religion or church community, 0 otherwise

1 if female, 0 if male

1 if participant lives together with partner, 0 otherwise

1 if participant indicates that their current work status is employed, 0 otherwise 1 if participant has at least one child living at home, 0 otherwise

1 if participant is in the 50 to 54 age group, 0 otherwise

1 if participant is in the 55 to 59 age group, 0 otherwise

1 if participant is born in the country in which (s)he lives, 0 otherwise

standardized measure for the personality trait extraversion, comprising two extraversion related questions from the TIPI questionnaire standardized measure for the personality trait neuroticism, comprising two neuroticism related questions from the TIPI questionnaire

standardized measure for the personality trait conscientiousness, comprising two conscientiousness related questions from the ten-item personality inventory (TIPI) questionnaire (Gosling et al., 2003)

standardized measure comprised of the following questions: "How do you see yourself: Are you generally a person who is fully prepared to take risks or do you try to avoid taking risks?"

\footnotetext{
Notes: Standardized measures are standardized with a zero mean and unit standard deviation.

${ }^{a}$ Measure is comprised of the answers to the following questions (scale 1: strongly disagree to 7 : strongly agree): (1) " $I$ am very knowledgeable about financial planning for retirement" (2) "I know more than most people about retirement planning" (3) "I am very confident in my ability to do retirement planning".

${ }^{b}$ Based on (1)-(3) from "Which of the following best describes our current work status?" (1) paid employment; (2) works or assists in family business; (3) autonomous professional, freelancer, or self-employed; (4) job seeker following job loss; (5) first-time job seeker; (6) exempted from job seeking following job loss; (7) attends school or is studying; (8) takes care of the housekeeping; (9) has (partial) work disability; (10) performs unpaid work while retaining unemployment benefit; (11) performs voluntary work; (12) does something else.
} 
Table 3: Descriptive statistics for the dependent and control variables

\begin{tabular}{|c|c|c|c|c|c|c|c|}
\hline \multirow[b]{2}{*}{ Dependent variables (indicators) } & \multicolumn{2}{|c|}{ Analysis Sample } & \multicolumn{2}{|c|}{ Australia } & \multicolumn{2}{|c|}{ The Netherlands } & \multirow[b]{2}{*}{$p$-value } \\
\hline & Mean & $\mathrm{Sd}$ & Mean & Std. Err. & Mean & Std. Err. & \\
\hline changed advised spending pattern & 0.291 & 0.45 & 0.315 & 0.015 & 0.273 & 0.011 & 0.026 \\
\hline implied endorsement prompts & 0.281 & 0.45 & 0.333 & 0.015 & 0.246 & 0.011 & 0.000 \\
\hline government advice prompt & 0.142 & 0.35 & 0.150 & 0.011 & 0.136 & 0.009 & 0.362 \\
\hline peer effect prompt & 0.181 & 0.38 & 0.232 & 0.013 & 0.145 & 0.009 & 0.000 \\
\hline government ranked above peer & 0.118 & 0.33 & 0.118 & 0.010 & 0.118 & 0.008 & 0.976 \\
\hline peer ranked above government & 0.164 & 0.37 & 0.215 & 0.013 & 0.129 & 0.008 & 0.000 \\
\hline Control variables (indicators) & Mean & $\mathrm{Sd}$ & Mean & $\mathrm{Sd}$ & Mean & $\mathrm{Sd}$ & \\
\hline \multicolumn{8}{|l|}{ Country of residence: } \\
\hline Australia & 0.41 & 0.49 & 1.00 & 0.00 & 0.00 & 0.00 & \\
\hline \multicolumn{8}{|l|}{ Financial resources } \\
\hline Household income (Q3 and Q4) & 0.32 & 0.47 & 0.34 & 0.47 & 0.31 & 0.46 & \\
\hline Homeowner & 0.78 & 0.42 & 0.83 & 0.37 & 0.74 & 0.44 & \\
\hline \multicolumn{8}{|l|}{ Future orientation } \\
\hline Time horizon: more than 5 years from now & 0.44 & 0.50 & 0.52 & 0.50 & 0.38 & 0.49 & \\
\hline \multicolumn{8}{|l|}{ Pension capability } \\
\hline Objectively measured & 0.24 & 0.43 & 0.34 & 0.47 & 0.18 & 0.39 & \\
\hline Self-assessed capability & 0.54 & 0.50 & 0.55 & 0.50 & 0.54 & 0.50 & \\
\hline \multicolumn{8}{|l|}{ Social network } \\
\hline age: $60-64$ & 0.32 & 0.46 & 0.23 & 0.42 & 0.37 & 0.48 & \\
\hline Religious / Member of a church community & 0.32 & 0.47 & 0.30 & 0.46 & 0.33 & 0.47 & \\
\hline
\end{tabular}

Additional control variables

\begin{tabular}{|c|c|c|c|c|c|c|}
\hline gender $=$ female & 0.50 & 0.50 & 0.50 & 0.50 & 0.50 & 0.50 \\
\hline marital status $=$ partner & 0.72 & 0.45 & 0.74 & 0.44 & 0.71 & 0.45 \\
\hline employed & 0.77 & 0.42 & 0.89 & 0.31 & 0.68 & 0.47 \\
\hline children living at home & 0.40 & 0.49 & 0.45 & 0.50 & 0.36 & 0.48 \\
\hline age: $50-54$ & 0.34 & 0.47 & 0.38 & 0.49 & 0.31 & 0.46 \\
\hline age: $55-59$ & 0.34 & 0.47 & 0.39 & 0.49 & 0.31 & 0.46 \\
\hline born in the country they are currently living in & 0.85 & 0.36 & 0.74 & 0.44 & 0.92 & 0.27 \\
\hline Control variables (standardized) & Min & Max & Mean & $\mathrm{Sd}$ & Mean & $\mathrm{Sd}$ \\
\hline personality: TIPI extraversion & -2.24 & 2.09 & -0.21 & 0.98 & 0.14 & 0.99 \\
\hline personality: TIPI neuroticism & -3.41 & 1.64 & -0.21 & 0.98 & 0.14 & 0.99 \\
\hline \multicolumn{7}{|l|}{ Personality } \\
\hline personality: TIPI conscientiousness & -4.11 & 1.52 & 0.17 & 0.94 & -0.12 & 1.02 \\
\hline risk aversion & -1.97 & 2.40 & 0.06 & 0.98 & -0.04 & 1.01 \\
\hline
\end{tabular}

2,420

983

1,437

Notes: The last column provides for the dependent variables the $p$-value for the two-sample test of proportions of the difference between the Australian and Dutch samples. Changed advised spending pattern equals one if the participant changed their advised spending pattern in the regulated drawdown vignette from the flexible drawdown vignette, and zero otherwise. The other dependent variables are derived from the responses to the flexible drawdown vignette. Implied endorsement prompts equals one if either government advice and/or peer effect motive is the first, second or third most important in the best/worst and zero otherwise. Government advice prompt (peer effect prompt) equals one if the government advice (or peer effect) motive is the first, second or third most important and zero otherwise. Government ranked above peer (peer ranked above government) equals one if the government advice (peer effect) motive is among the top three and to be ranked above the peer effect (government advice) motive and zero otherwise. The control variables are described in Table 2 . 
ernment advice and/or peer effect saving motive is ranked first, second or third most important in the best/worst choice task, and zero otherwise. Hence, if the implied endorsement prompt does equal one, at least one of the implied endorsement savings motives alters their (imputed) top three savings motives from the flexible drawdown vignette.

- Second, the variable government advice prompt (peer effect prompt) equals one if the government advice (peer effect) saving motive is ranked first, second or third most important in the best/worst choice task, and zero otherwise.

- Finally, the variable government ranked above peer (peer ranked above government) equals one if the government advice (peer effect) savings motive is among the top three and ranked above the peer effect (government advice) saving motive and zero otherwise. Hence, if the variable implied endorsement prompts equals one, either government ranked above peer equals one or the variable peer ranked above government equals one, but not both.

Almost $30 \%$ of participants amended their (imputed) top three savings motives by incorporating an implied endorsement saving motive (see top panel of Table 3) as they moved from the flexible drawdown vignette to the regulated drawdown vignette. There are significant country differences. Around one third of the Australian sample included an implied endorsement savings motive in their top three, whereas only a quarter of the Dutch sample did so. The country difference is likely driven by a difference in the prevalence of the peer effect implied endorsement motive, while the government advice implied endorsement motive occurs equally in both countries.

The prevalence of both implied endorsement savings motives (i.e., the "government advice" motive and the "peer effect" motive) among the top three is low. Therefore, the mean of government ranked above peer and peer ranked above government are typically only less than two percentage points lower than the government advice prompt and peer effect prompt. The exception is government ranked above peer in Australia, which is 3.2 percentage points lower than the government advice prompt.

\subsection{Control variables}

Table 3 also reports the descriptive statistics for the main control variables in the analysis sample. We group these in terms of financial resources, future orientation, pension capability, social network, additional controls and country of residence. Our measures of financial resources are household income and home ownership. The proportion of participants with high income is similar in both the Dutch and Australian samples. However, reflecting country differences, Australian participants are more likely to be homeowners than the Dutch. Most older Australians own their home and only a minority rent while in the Netherlands there is a large social housing pool with substantial renter's protection and low rents.

For future orientation, we observe from our sample that Australians tend to be more future oriented. A likely explanation for this is that the Australian retirement 
system places more responsibility on individuals, making it more important to plan long term, while the Dutch retirement system offers little choice and individual responsibility.

For pension capability, we find that Australians made less mistakes in the financial literacy, numeracy and pension literacy questions and thus score higher on the objective measure of pension capability. ${ }^{11}$ This might be because they had greater exposure to financial decisions in their real world retirement income system. However, there is no difference in self-assessed pension capability on average between the Australian and Dutch samples. ${ }^{12}$ In terms of proxies for social networks, we observe from our sample that, on average, the Dutch are less likely to be employed ${ }^{13}$ and slightly more likely to consider themselves to be members of a religion or church community.

Finally, we also observe that the Australian participants as compared to Dutch participants are on average slightly less likely to be single, more likely younger, more likely to have at least one child living at home and more risk loving. The Dutch are more likely to be born in the country they live in and score higher for the personality traits extraversion and neuroticism, but lower for conscientiousness.

\section{Estimation results}

Our empirical analysis has two main aims. The first aim is to investigate whether a government regulated retirement drawdown is implied endorsement for retirement spending, and, if this is so, whether this is because the government regulated drawdown is interpreted as implicit advice from government or as being indicative of what most other people do (a peer effect). We analyse this by investigating the relative effectiveness of the government advise prompt compared to the peer effect prompt. A prompt is more effective when it alters the advised spending pattern more often and the adjustment is in the expected direction. The analysis is presented in Section 4.1 .

The second aim is to identify which personal characteristics lead individuals to be more sensitive to implied endorsement. Typically, a nudge is designed so as to protect vulnerable people from making decisions which would substantially reduce their utility. Therefore, we investigate whether participants who are more sensitive

\footnotetext{
${ }^{11}$ In the analysis sample the average number of mistakes in the financial literacy questions were 0.85 (min.: 0; max.: 3) (AUS: 0.65; NLD: 0.98), for the numeracy questions 1.23 (min.: 0; max.: 3) (AUS: 1.16; NLD: 1.27) and for the pension knowledge questions 1.54 (AUS: 1.22; NLD: 1.75) (min.: 0; max.: 4). Thus, a participant in the analysis sample is considered to have objectively measured pension capabilities if (s)he has 0 mistakes in the financial literacy questions, at most 1 mistake in the numeracy questions and at most 1 mistake in the pension knowledge questions.

${ }^{12}$ The unstandardized self-assessed pension capability is the average score of the two questions on self-assessed pension capabilities in Table 2. For the analysis sample, the average score on question (1) is 4.04 (AUS: 3.65; NLD: 4.30) whereas for question (2) this is 3.98 (AUS: 4.17; NLD: 3.85). Internal consistency in responses of these questions is good - the Cronbach alpha is 0.85 (AUS: 0.89; NLD: 0.82).

${ }^{13}$ This difference is most likely driven by the lower labour force participation rates for women in the Netherlands - see Euwals et al. (2011).
} 
to the implied endorsement nudge are in fact the vulnerable people we would expect to be in this target group. The analysis is presented in Section 4.2.

We examine both research aims by estimating Logit regression models (as per Cameron and Trivedi, 2005) and present our results for the analysis sample and by each country to check whether findings can be generalized. ${ }^{14}$ Our analysis indicates that, even after controlling for a rich set of covariates, there remain country differences in the effect of the implied endorsement nudge on the advised spending and saving behaviour. Our main specification also includes a set of nuisance parameters to account for the different sets of five saving motives presented to the participants. ${ }^{15}$ In Section 4.3 a series of robustness checks analyses the sensitivity of our results to two aspects of the experimental design - the importance of the order in which the flexible drawdown vignette is presented ${ }^{16}$ and cognitive effort of the participant. $^{17}$

\subsection{For whom is implied endorsement more effective?}

The implied endorsement nudge (that is, the regulated drawdown requirement), provided in two additional sentences in the regulated drawdown vignette (as compared to the flexible drawdown vignette), has a substantial impact on the spending trajectory advised by participants. The descriptive statistics (cf. Section 3) show that, after presentation of the nudge, around $30 \%$ of participants altered their advised spending pattern and a similar proportion altered their top three savings motives by including an implied endorsement savings motive. Related to the propensity to change the spending pattern (between the regulated drawdown vignette and the flexible drawdown vignette), we test two hypotheses.

First, we hypothesize that participants who are sensitive to the implied endorsement nudge are more likely to alter their advised spending pattern than those who do not indicate sensitivity. On the one hand, one could imagine that individuals place greater value on advice from their closest relatives and friends - who are more aware of their personal circumstances - than from the government - who can only design and communicate one-size-fits-all advice. On the other hand, however, the government

\footnotetext{
${ }^{14}$ For the country specific regressions the covariates are standardized per country, whereas in Table 3 standardization is for the analysis sample. Thus, rather than reported in Table 3, the mean (standard deviation) for, for example, "personality: TIPI conscientiousness" in the Netherlands would now equal 0 (1).

${ }^{15}$ Nuisance parameters are modelled as binary variables to account for the different set of five saving motives presented to a participant as a result of the randomization procedure. Our results appear robust to a specification without nuisance parameters (cf. column (5), (11) and (17) in Table 7 in Section 4.3).

${ }^{16}$ The two vignettes analysed in this study are in the first set of a larger experiment of two sets of four vignettes. In this first set the regulated drawdown vignette is always presented fourth, but the flexible drawdown vignette is randomly assigned to be presented first, second or third. As such participants are presented the flexible drawdown and regulated drawdown vignettes sequentially but not necessarily consecutively.

${ }^{17}$ As an additional robustness check, we look at the sensitivity of our results to different distributional assumptions (a Probit model and a Linear Probability Model). Our results appear robust to a specification with a different distributional assumption (cf. Table A.3 in the supplementary material.
} 
might be more capable of determining the optimal spending pattern for types of individuals than peers. The descriptive statistics in Table 3 indicate that the "peer effect" motive (i.e., the indicator peer ranked above government) is likely to be more important than the "government advice" motive (i.e., the indicator government ranked above peer). This is especially the case for the Australian participants who would have some real world familiarity with similar decisions.

Second, we hypothesize that the "government advice" motive (i.e., the indicator government ranked above peer) is more effective in increasing spending than the "peer effect" motive (i.e., the indicator peer ranked above government). In the nudge we implement, the government sets a minimum withdrawal level, which could translate to advice from the government to spend a relatively large amount of retirement wealth. ${ }^{18}$

We test the hypotheses by performing a Logit regression with the endogenous indicator variable changed the advised spending pattern (Table 4) and the indicator whether the advised spending pattern has increased (Table 5). We test the first hypothesis that participants who are sensitive to the implied endorsement are more likely to alter their advised spending pattern than those who do not indicate sensitivity by regressing the indicator variable changed the advised spending pattern on the implied endorsement prompts (odd columns in Table 4). A significant regression coefficient for the implied endorsement prompts variable would indicate that the hypothesis would hold. We test the second hypothesis that the "government advice" motive is more effective in changing advised spending than the "peer effect" motive by regressing the indicator variable changed the advised spending pattern on the peer ranked above government and government ranked above peer (even columns in Table 4). A significant larger regression coefficient for the government ranked above peer variable than the peer ranked above government variable would indicate that the hypothesis would hold.

The first two columns for each country present the results for the regression without additional control variables, while the second two columns per country include additional control variables. Note that the top panel in Table 4 includes individuals with the highest (lowest) advised spending pattern in the flexible drawdown vignette, who cannot increase (decrease) their spending pattern in the regulated drawdown vignette. This is the case for 168 Australian participants and 325 Dutch participants. Therefore, the lower panel presents the estimation results excluding those individuals. ${ }^{19}$

\footnotetext{
${ }^{18}$ It could be argued that if participants were to follow the nudge in the intended direction, their preference would align more closely to the theoretical results related to consumption smoothing over the life cycle, as they do not hold on to or hold on less to their wealth throughout retirement. Various empirical studies find that individuals tend to hold on to their wealth throughout retirement (Asher et al., 2017; Van Ooijen et al., 2015). According to De Nardi et al. (2016), the elderly deviate from the "optimal" consumption path implied by theoretical life cycle models because of precautionary savings motives and the intended bequest motive. To analyse why individuals prefer to hold on to their wealth, is beyond the scope of this paper.

${ }^{19}$ In the supplementary material the parameter estimates of the model excluding individuals who advised the highest spending pattern in the flexible drawdown vignette (upper panels) and the parameter estimates of the model excluding individuals who advised the lowest spending pattern in the flexible drawdown vignette (lower panels) are provided in Table A.1 for the propensity to change advised spending pattern and in Table A.2. for the propensity to increase advised spending
} 


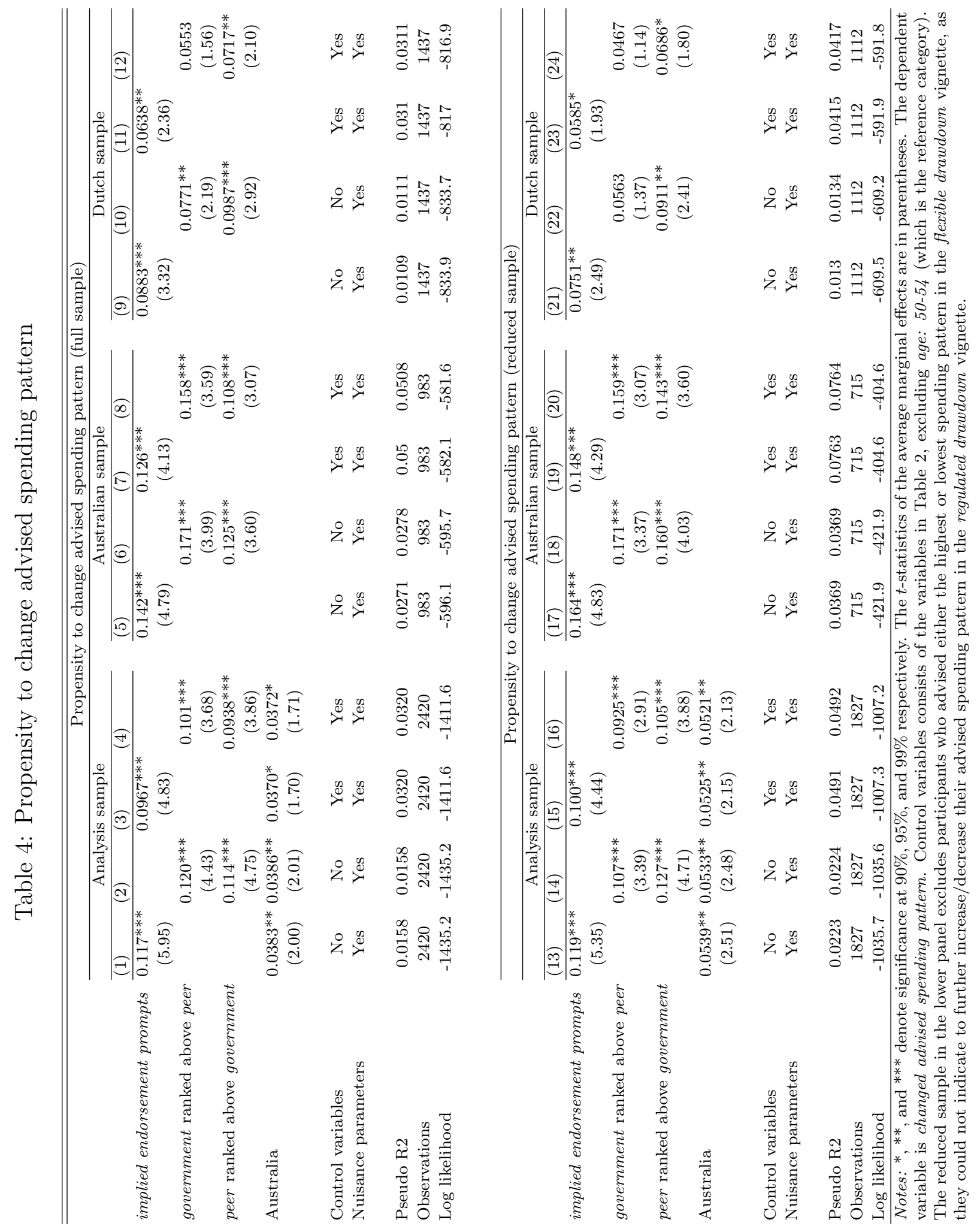


We find evidence that the first hypothesis, that participants who are sensitive to the implied endorsement are more likely to alter their advised spending pattern than those who do not indicate sensitivity holds. We observe from Table 4 that participants who indicate that at least one of the implied endorsement motives (either the "peer effect" or "government advice" motive) rank among the top three have a higher propensity to change their advised spending pattern. The effect is around two to three times the effect of the country of residence and is larger for Australian participants than for the Dutch participants. The difference in the effect of the implied endorsement motive on the propensity to increase spending between the Dutch and Australians is primarily due to the effect of the "government advice" motive. The effect of the "peer effect" motive is more similar.

The Australian participants who indicate that the "government advice" motive is (somewhat) important to them (i.e., government ranked above peer equals one) have a higher propensity to change their spending pattern than those who indicate that the "peer effect" motive is (somewhat) important (i.e., peer ranked above government equals one). For the Dutch participants it is the opposite. This might be due to familiarity with implied endorsement. Indeed, the estimates of the dummy variable Australia indicate that Australians are more likely to indicate to change their spending pattern than the Dutch. Outside the experimental set-up, Australians are required to make an active choice about the decumulation of their retirement wealth while the Dutch are required to fully annuitize. Hence, it is more likely that (in the real world) Australians discuss their choice options with their peers (such as whether or not their spending should follow the tax-preferred minimum withdrawal rates) thereby leading to more sizeable effects for the implied endorsement motive covariates. Controlling for a large set of observable characteristics slightly decreases the size of the effect of the implied endorsement nudge on holding advised spending constant, but has little effect on its significance.

We do not find evidence that the second hypothesis, that the "government advice" motive is more effective in increasing spending than the "peer effect" motive. We do not obtain statistically significant evidence that the "government advice" motive is more effective at increasing the spending level in retirement than the "peer effect" motive. The estimate of the government ranked above peer variable (see Table 5) is of the expected sign for the Australian sample, but not statistically significant, except in the reduced sample without other control variables (column (18)). However, in the Dutch sample the effect of the government ranked above peer variable is of the opposite sign than expected and significant for the reduced sample (columns (22) and (24)). We have identified two potential explanations for the lack of significance for Australian participants and the opposite sign for the Dutch. First, we hypothesize that it is due to the word "require" in the regulated drawdown vignette, which could suggest to participants that the hypothetical households should always be able to withdraw the amount of wealth as suggested by the government, even after they run out of money at advanced age. This might be more relevant for the Dutch who are less familiar with a government regulated drawdown. Second, the result may be due to the limited number of observations, as we restrict our sample to

pattern given change in advised spending pattern. 


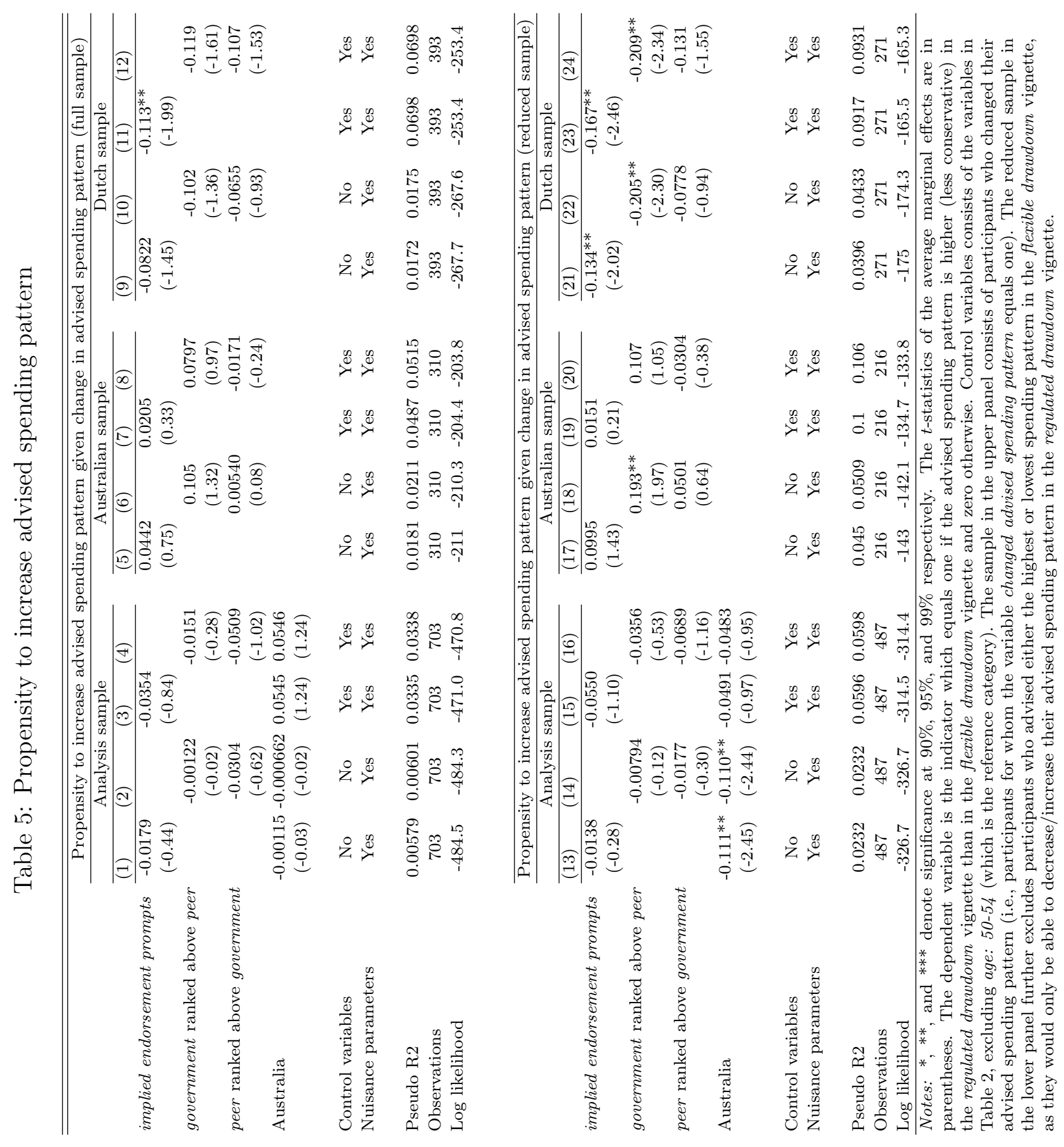


only participants who have changed their spending pattern, which makes it harder to observe significant effects.

\subsection{Who is more sensitive to the implied endorsement prompt?}

Libertarian paternalism allows individuals to make their own decisions while providing guidance to prevent the more vulnerable from making decisions which could be inappropriate for them (that is, would diminish their utility). Therefore, it is important to investigate who is more sensitive to the implied endorsement provided by the nudge to spending in retirement (that is, to follow the government prescribed minimum drawdown). To do so, we estimate a Logit regression with the dependent variable being whether either at least one of the implied endorsement prompts - the "peer effect" and "government advice" motives - are among the top three savings motives nominated by the participant in the regulated drawdown vignette. Table 6 presents the average marginal effects for the importance of the implied endorsement prompts (columns (1)-(3)), the government advice prompt (columns (4)-(6)) and the peer effect prompt (columns (7)-(9)) for the analysis sample and each of the Australian and Dutch samples. The table displays the results for covariates that are proxies for groups who are more vulnerable to making choices which negatively impact their utility as measured by financial resources, future orientation, pension capability and personality. In addition, we investigate the impact of participant's social networks as this might explain the effectiveness of the peer effect. Other control variables and nuisance parameters are included in the estimation, but the parameter estimates are not shown in this table.

\section{Financial resources}

In line with our expectations, those with fewer financial resources find the implied endorsement nudge more important in their spending and savings decisions. This is the typical group for whom nudges are designed. The proxies for having high financial resources - belonging to the highest two income categories and owning a house - decrease the likelihood of finding the "government advice" and "peer effect" prompts important. Whereas the income variable is typically statistically significant, the effect of being a homeowner is smaller and only significant at a $10 \%$ level for the dependent variable implied endorsement prompts in the analysis sample. These results are in line with Beshears et al. (2016), albeit in a slightly different setting, who find that individuals below the age of 34 when they were first hired, as well as those with low incomes, are more likely to follow the implied endorsement nudge, even after controlling for contribution rate preferences.

\section{Future orientation}

Another group who are more vulnerable to choose an option which could substantially reduce their utility are individuals who do not plan for the future. Such behaviour might induce individuals to spend too little, as they might be concerned about outliving their wealth. Indeed, the minimum drawdown rates for retirement wealth in Australia are designed to encourage consumption, reduce the accumulation of assets in retirement and therefore increase or maintain their living standards 
Table 6: Main results for the importance of the "government advice" and "peer effect" prompts. Average marginal effects based on Logit estimates

\begin{tabular}{|c|c|c|c|c|c|c|c|c|c|}
\hline & \multicolumn{3}{|c|}{ implied endorsement prompts } & \multicolumn{3}{|c|}{ government advice prompt } & \multicolumn{3}{|c|}{ peer effect prompt } \\
\hline & $\begin{array}{c}\text { Analysis sample } \\
(1)\end{array}$ & $\begin{array}{c}\text { Australia } \\
(2)\end{array}$ & $\frac{\text { The Netherlands }}{(3)}$ & $\begin{array}{c}\text { Analysis sample } \\
(4)\end{array}$ & $\begin{array}{c}\text { Australia } \\
(5)\end{array}$ & $\begin{array}{c}\text { The Netherlands } \\
(6)\end{array}$ & $\begin{array}{c}\text { Analysis sample } \\
(7)\end{array}$ & $\begin{array}{c}\text { Australia } \\
(8)\end{array}$ & $\begin{array}{c}\text { The Netherlands } \\
(9)\end{array}$ \\
\hline $\begin{array}{l}\text { Country of Residence } \\
\text { Australia }\end{array}$ & $\begin{array}{c}0.108^{* * *} \\
(5.24)\end{array}$ & & & $\begin{array}{c}0.0324^{*} \\
(1.94)\end{array}$ & & & $\begin{array}{c}0.0933^{* * * *} \\
(5.28)\end{array}$ & & \\
\hline Financial resources & & & & & & & & & \\
\hline $\begin{array}{l}\text { Household income } \\
\text { (Q3 and Q4) } \\
\text { Homeowner }\end{array}$ & $\begin{array}{c}-0.0840 * * * \\
(-3.93) \\
-0.0400^{*} \\
(-1.81)\end{array}$ & $\begin{array}{c}-0.0985 * * * \\
(-2.91) \\
-0.0301 \\
(-0.76)\end{array}$ & $\begin{array}{c}-0.0613^{* *} \\
(-2.20) \\
-0.0391 \\
(-1.48)\end{array}$ & $\begin{array}{c}-0.0618^{* * *} \\
(-3.47) \\
-0.0154 \\
(-0.90)\end{array}$ & $\begin{array}{c}-0.0989 * * * \\
(-3.61) \\
-0.0214 \\
(-0.75)\end{array}$ & $\begin{array}{c}-0.0222 \\
(-0.95) \\
-0.0134 \\
(-0.61)\end{array}$ & $\begin{array}{c}-0.0629 * * * \\
(-3.37) \\
-0.0269 \\
(-1.42)\end{array}$ & $\begin{array}{c}-0.0463 \\
(-1.50) \\
-0.00873 \\
(-0.24)\end{array}$ & $\begin{array}{c}-0.0691 * * * \\
(-2.83) \\
-0.0304 \\
(-1.42)\end{array}$ \\
\hline $\begin{array}{l}\text { Future orientation } \\
\text { Time horizon: more } \\
\text { than } 5 \text { years from now } \\
\text { Pension capability }\end{array}$ & $\begin{array}{c}-0.0260 \\
(-1.45)\end{array}$ & $\begin{array}{c}-0.0574^{* *} \\
(-2.01)\end{array}$ & $\begin{array}{c}0.00339 \\
(0.15)\end{array}$ & $\begin{array}{c}-0.0164 \\
(-1.14)\end{array}$ & $\begin{array}{c}-0.0480^{* *} \\
(-2.20)\end{array}$ & $\begin{array}{c}0.00897 \\
(0.48)\end{array}$ & $\begin{array}{c}-0.0310^{* *} \\
(-1.99)\end{array}$ & $\begin{array}{c}-0.0396 \\
(-1.51)\end{array}$ & $\begin{array}{c}-0.0189 \\
(-0.98)\end{array}$ \\
\hline $\begin{array}{l}\text { Objectively measured } \\
\text { Self-assessed } \\
\text { capability }\end{array}$ & $\begin{array}{c}-0.128 * * * \\
(-5.63) \\
0.0228 \\
(1.24)\end{array}$ & $\begin{array}{c}-0.132^{* * *} \\
(-4.06) \\
0.0585^{*} \\
(1.95)\end{array}$ & $\begin{array}{c}-0.140 * * * \\
(-4.12) \\
-0.00147 \\
(-0.06)\end{array}$ & $\begin{array}{c}-0.0704^{* * *} \\
(-3.67) \\
0.00532 \\
(0.37)\end{array}$ & $\begin{array}{c}-0.0843^{* * *} \\
(-3.16) \\
0.0313 \\
(1.38)\end{array}$ & $\begin{array}{c}-0.0576^{* *} \\
(-2.08) \\
-0.0173 \\
(-0.91)\end{array}$ & $\begin{array}{c}-0.102^{* * *} \\
(-4.99) \\
0.0210 \\
(1.33)\end{array}$ & $\begin{array}{c}-0.104 * * * \\
(-3.42) \\
0.0474^{*} \\
(1.72)\end{array}$ & $\begin{array}{c}-0.126^{* * *} \\
(-3.88) \\
0.00601 \\
(0.32)\end{array}$ \\
\hline $\begin{array}{l}\text { Social network } \\
\text { age: } 60-64\end{array}$ & $\begin{array}{c}-0.0174 \\
(-0.75)\end{array}$ & $\begin{array}{c}-0.00540 \\
(-0.14)\end{array}$ & $\begin{array}{c}-0.0220 \\
(-0.76)\end{array}$ & $\begin{array}{l}0.0221 \\
(1.20)\end{array}$ & $\begin{array}{l}0.0378 \\
(1.29)\end{array}$ & $\begin{array}{l}0.0126 \\
(0.53)\end{array}$ & $\begin{array}{c}-0.0371 * \\
(-1.87)\end{array}$ & $\begin{array}{c}-0.0224 \\
(-0.64)\end{array}$ & $\begin{array}{c}-0.0470^{* *} \\
(-1.97)\end{array}$ \\
\hline $\begin{array}{l}\text { Religious / Member of } \\
\text { a church community } \\
\text { Personality }\end{array}$ & $\begin{array}{c}0.0179 \\
(0.96)\end{array}$ & $\begin{array}{r}0.0311 \\
(0.99)\end{array}$ & $\begin{array}{c}0.00651 \\
(0.28)\end{array}$ & $\begin{array}{c}-0.00614 \\
(-0.41)\end{array}$ & $\begin{array}{c}-0.0263 \\
(-1.06)\end{array}$ & $\begin{array}{c}0.00284 \\
(0.15)\end{array}$ & $\begin{array}{c}0.0283^{*} \\
(1.76)\end{array}$ & $\begin{array}{l}0.0416 \\
(1.47)\end{array}$ & $\begin{array}{l}0.0182 \\
(0.95)\end{array}$ \\
\hline $\begin{array}{l}\text { personality: TIPI } \\
\text { conscientiousness } \\
\text { risk aversion }\end{array}$ & $\begin{array}{c}-0.0234^{* *} \\
(-2.57) \\
0.0201 * * \\
(2.18)\end{array}$ & $\begin{array}{c}-0.0173 \\
(-1.16) \\
0.0233 \\
(1.53)\end{array}$ & $\begin{array}{c}-0.0224^{* *} \\
(-2.01) \\
0.0178 \\
(1.57)\end{array}$ & $\begin{array}{c}-0.0260 * * * \\
(-3.71) \\
0.00408 \\
(0.56)\end{array}$ & $\begin{array}{c}-0.0461 * * * \\
(-4.35) \\
0.00391 \\
(0.34)\end{array}$ & $\begin{array}{c}-0.00986 \\
(-1.08) \\
0.00408 \\
(0.44)\end{array}$ & $\begin{array}{c}0.000413 \\
(0.05) \\
0.0211^{* * *} \\
(2.64)\end{array}$ & $\begin{array}{c}0.0208 \\
(1.48) \\
0.0244^{*} \\
(1.76)\end{array}$ & $\begin{array}{c}-0.00862 \\
(-0.94) \\
0.0190^{* *} \\
(2.02)\end{array}$ \\
\hline $\begin{array}{l}\text { Additional control } \\
\text { Nuisance parameters }\end{array}$ & $\begin{array}{l}\text { Yes } \\
\text { Yes }\end{array}$ & $\begin{array}{l}\text { Yes } \\
\text { Yes }\end{array}$ & $\begin{array}{l}\text { Yes } \\
\text { Yes }\end{array}$ & $\begin{array}{l}\text { Yes } \\
\text { Yes }\end{array}$ & $\begin{array}{l}\text { Yes } \\
\text { Yes }\end{array}$ & $\begin{array}{l}\text { Yes } \\
\text { Yes }\end{array}$ & $\begin{array}{l}\text { Yes } \\
\text { Yes }\end{array}$ & $\begin{array}{l}\text { Yes } \\
\text { Yes }\end{array}$ & $\begin{array}{l}\text { Yes } \\
\text { Yes }\end{array}$ \\
\hline $\begin{array}{l}\text { Pseudo R2 } \\
\text { Observations } \\
\text { Log likelihood }\end{array}$ & $\begin{array}{c}0.0889 \\
2420 \\
-1310.4\end{array}$ & $\begin{array}{l}0.0892 \\
983 \\
-569.5\end{array}$ & $\begin{array}{l}0.101 \\
1437 \\
-721.0\end{array}$ & $\begin{array}{l}0.0668 \\
2420 \\
-921.6\end{array}$ & $\begin{array}{c}0.123 \\
983 \\
-363.9\end{array}$ & $\begin{array}{c}0.0629 \\
1437 \\
-536.5\end{array}$ & $\begin{array}{c}0.0845 \\
2420 \\
-1046.3\end{array}$ & $\begin{array}{l}0.0722 \\
983 \\
-494.0\end{array}$ & $\begin{array}{c}0.102 \\
1437 \\
-535.1\end{array}$ \\
\hline
\end{tabular}

Notes: $*, * *$, and $* * *$ denote significance at $90 \%, 95 \%$, and $99 \%$ respectively. The $t$-statistics of the average marginal effects are in parentheses. The dependent variable is implied endorsement prompts for columns (1)-(3), government advise prompt for columns (4)-(6) and peer effect prompt for columns (7)-(9). Additional control consists of gender = female, marital status, employed, age: 55-59 (age: 50-54 is the reference category), having children living at home, born in the country they are currently living in, personality (measures of TIPI extraversion, and neuroticism - standardized). Pension capabilities only consist of two measures. The variable Objectively measured: is a combined measure that equals 1 if respondent made less mistakes than the average of the population in the financial literacy, numeracy, and pension system knowledge related questions, and 0 otherwise. The variable Self-assessed: is a combined measure that equals 1 if respondent is more confident in his/her own pension related capability than the average of the population, and 0 otherwise. Measure is comprised of the answers to the following questions (scale 1: strongly disagree to 7: strongly agree): (1) I am very knowledgeable about financial planning for retirement (2): I know more than most people about retirement planning (3): I am very confident in my ability to do retirement planning. 
during retirement compared to their working life.

This closely resembles our experimental setting where following the government regulated drawdown nudge implies (more than) the highest spending level during retirement, which reduces savings accordingly. For the Australian sample we find that those who plan less are more inclined to follow the implied endorsement nudge, although the effect is not significant for the peer effect prompt. By contrast, for the Dutch we find that planning does not explain attitude towards the implied endorsement motives. This might be because being future oriented could have two opposing effects on saving and spending decisions. On the one hand, those who are future oriented have probably thought about their financial arrangements during retirement and are therefore less inclined to find the implied advice and the related saving motive important. That Australians have more options for choice in their actual retirement savings arrangement than the Dutch could explain why this effect is larger for the Australian sample. On the other hand, those who have a higher present bias, and are thus less future oriented, are more likely to prefer a higher spending level and could prefer to follow the nudge as it provides a justification for a high spending pattern without having to put in effort to determine a spending pattern themselves.

\section{Pension capability}

Another group of individuals are those who have limited capability to make the cognitively difficult decision of how much to draw down in retirement. We consider two measures of pension capability. In the first we combine questions on financial literacy, numeracy and pension system knowledge to construct the variable Objectively measured based on whether participants answer these questions correctly or not. Table 6 shows that those scoring higher than the average of the (country specific) analysis sample on objectively measured pension capability are less likely to find the "government advice" and "peer effect" prompts important. In a related context, Agnew and Szykman (2005) find that individuals with low knowledge of financial matters more often opt for a default asset allocation in 401(k) plans. Our findings suggest that financial knowledge has a similar relationship with the importance of the "government advice" and "peer effect" prompts.

In contrast to the effect of objectively measured pension capabilities, a higher than average score for self-assessed pension knowledge is associated with a higher importance of the "government advice" and "peer effect" prompts. However, the effect is typically not significant, except in the Australian sample at a $10 \%$ level. The sign of self-assessed capability is striking, as those who are less confident about their financial capability and pension knowledge, would be expected to be more likely to indicate that either the "government advice" or "peer effect" prompts are of value for their decision making. We hypothesize that the positive effect of self-assessed capability is due to participants who overestimate their capabilities. For instance, overconfidence is associated with a lower allocation to products offering longevity protection (Bateman et al., 2018). ${ }^{20}$

\footnotetext{
${ }^{20}$ In the supplementary materials, we test what drives the positive effect for self-assessed capability by re-estimating the model with indicators to identify to which of four groups of individuals, based on their objectively and subjectively measured pension capabilities, the participant belongs.
} 


\section{Social network}

Having a good social network is a prerequisite for the "peer effect" motive. Having more, and closer, connections would potentially increase the likelihood that people discuss financial matters with peers and follow their advice. The social network effect could be captured through several channels, including marital status, having children living at home, employment status and belonging to a religion. ${ }^{21}$

The size and quality of the social network should not impact the importance of the "government advice" motive. Indeed, the variables related to the social network of participants do not have a statistically significant effect on the importance of the government advice prompt at conventional levels of significance. Given the small effects on the peer effect prompt and no effect on the government advice prompt, there is also no significant effect on the social network of including at least one implied endorsement motive in their top three spending and saving motives.

We find that having a social network is important for the "peer effect" motive for the analysis sample and the Dutch sample, but not the Australian sample. Our results align with existing studies on the influence of peer effects on (retirement) savings outcomes (Duflo and Saez, 2003; Beshears et al., 2015; Breza and Chandrasekhar, 2019). For the Dutch, the parameter estimates indicate that that being older significantly negatively affects the importance of the "peer effect" motive. Older participants typically have smaller social networks: a meta-analysis by Wrzus et al., 2013 found that a social network decreases for older people in adulthood. The effect is smaller in the Australian sample as -given the choice in retirement income provision products in Australia- those older participants are more likely to have already discussed their retirement financing plans with some of their peers at younger ages.

Being religious or a member of a church community is beneficial for the effect of the "peer effect" motive, however, only at a $10 \%$ significance level in the analysis sample. Religious people typically have a strong social network through their church community.

\section{Personality}

Participants who are more conscientious are less likely to find the "government advice" motive important. ${ }^{22}$ While this effect is significant even at a level of confidence of $1 \%$ for the Australian sample, the effect is small for the Dutch and not significant. The large effect in Australia could be due to Australians viewing the government

\footnotetext{
We find that our conjecture is likely to hold.

${ }^{21}$ The channels of the social network through marital status and having children living at home are included as control variables as we consider them as second order effects. These control variables would require additional connections through the partner or children to have an effect on spending and saving decisions. For these variables we do not observe statistically significant effects.

${ }^{22} \mathrm{~A}$ more formal interpretation of the marginal effects is as follows. For example, on average, a one-unit increase in "Australia" - the country of residence of the participant - increases the probability the participant would indicate that the "government advice" motive is among the top three motives by $3.24 \%$ (column (4) in Table 6). Note that this "one-unit" interpretation does not generally hold for our continuous variables "personality: TIPI conscientiousness" and "risk aversion". However, as we have standardized our continuous variables, this interpretation should therefore remain (more or less) valid.
} 
as having the conflicting goals of assisting individuals in their retirement income provision but at the same time trying to restrict government spending by reducing tax concessions for retirement saving. Since the Dutch have no experience with the latter, it would have no effect on them. However, given the continuous alterations to superannuation tax concessions in Australia in recent decades, conscientious participants might have a lower trust that the government has the right thing in mind when constructing the implied endorsement. As peers are not subject to suspicions about their motives, the effect is not present for the "peer effect" motive.

Those with higher risk aversion are more likely to follow their peers. Given that people compare their standard of living with their peers, having a different spending pattern to their peers would imply the risk that one would be relatively worse off. Participants who have a higher than average risk aversion therefore are more likely to follow their peers. Therefore, risk aversion is significant for the peer effect prompt. As the social comparison is based on someone's peers not the government advice, risk aversion is not significant for the government advice prompt.

\subsection{Robustness checks}

In this section we discuss what drives the pension capability measure. In addition, we analyse the sensitivity of our results to two experimental design features: the importance of the realized ordering of the varying levels of liquid wealth vignettes, and the effect of cognitive effort. Participants who were presented the flexible drawdown vignette immediately prior to the regulated drawdown might be more aware of what they answered in the flexible drawdown vignette compared to others, thereby potentially affecting our estimation results. We also assess the sensitivity of our results to the inclusion of the additional control variables and nuisance parameters. ${ }^{23}$

We only discuss the robustness checks for the analysis sample as the differences between the country-specific results are negligible. The results per country can be found in the supplementary materials (Table A.6. and A.7).

\subsubsection{Decomposing objectively measured pension capability}

Table 6 shows that objectively measured pension capability is not only significant for both prompts and countries, but has a sizeable effect. To assess the drivers of

\footnotetext{
${ }^{23}$ As pointed out by a referee, the self-employed may have different motives to save (preretirement) than employees. We expect, however, that any difference would become less once the self-employed are retired, and by properly accounting for observable characteristics. As a robustness check, we identify the self-employed (NLD: $6.5 \%$ of participants; AUS: $8.5 \%$ of participants) in our variable employed and rerun the regressions for Table 4, 5 and 6 with this newly constructed variable as an additional control (results available upon request). Our variables of interest (i.e. related to financial resources, future orientation, pension capability, social network and personality) are little affected by explicitly accounting for the self-employed. There does remain an effect with regards the self-employed for the importance of the "government advice" and "peer effect" prompts. For the Dutch sample, the self-employed, compared to the employed, are generally less likely to find the government advice prompt important, whereas the self-employed in the Australian sample find both the peer effect and government advice prompt less important.
} 
this effect we decompose the measure into its constituent parts - financial literacy, numeracy and knowledge of the pension system - and re-estimate the model. The results are presented in Table 7, columns (1), (7), and (13).

The results indicate that numeracy contributes most to the importance of the pension capability measure for both the peer effect prompt and the government advice prompt. The size of the effect of numeracy is closely followed by the size of the effect of financial literacy and pension system knowledge for the peer effect prompt. The size of the pension system knowledge effect for the government advice prompt is small and the variable is not statistically significant.

\subsubsection{Design elements of the implied endorsement vignette}

As discussed earlier, this study focusses on the differences in choices and motives between two vignettes from eight presented to participants in the full experiment. In the full experiment the regulated drawdown vignette is always presented fourth, but the flexible drawdown vignette is randomly assigned to be presented first, second or third. These three vignettes differed by the mix of liquid wealth and annuitization. As such, some of our estimation results could be driven by ordering effects (two conjectures) and cognitive exhaustion (one conjecture). Our survey design allows us to test these three conjectures and the results are presented in Table 7.

First, participants who were presented with the flexible drawdown vignette immediately prior to the regulated drawdown vignette, could respond differently in the regulated drawdown vignette as they are more likely to be aware of what they answered in the previous vignette, compared to participants who saw the flexible drawdown vignette earlier in the sequence. To test his conjecture, we constructed the indicator variable vignette prior that equals one if the third vignette presented was the flexible drawdown vignette, and zero otherwise. Table 7, columns (2), (8), and (14) shows that this indicator variable is not significant and that our results are robust to the flexible drawdown vignette being presented to the participant immediately prior to the regulated drawdown vignette.

Second, as the first three vignettes were framed in either an Australian or a Dutch institutional setting (or a hybrid), if the participant first advised a spending pattern in a familiar retirement system setting, this could lead to different outcomes as opposed to a (similar) participant who first advised in an unfamiliar retirement system setting. While in this study we are only concerned with the flexible drawdown vignette and regulated drawdown vignette, the order in which they saw the flexible drawdown vignette could potentially affect our results if familiarity with the liquidity setting appears to influence the importance of the implied endorsement prompts. Australian participants are likely to be familiar with the flexible drawdown vignette and the Dutch more familiar with the vignette which has a high level of annuitization (the retirement income vignette - not analysed in this study). To test the second conjecture, we constructed an indicator variable familiar first vignette that equals one if the first choice task presented to the Australian participants was the flexible drawdown vignette to the Dutch participants the retirement income vignette, and zero otherwise. From Table 7, columns (3), (9), and (15), we observe that this 


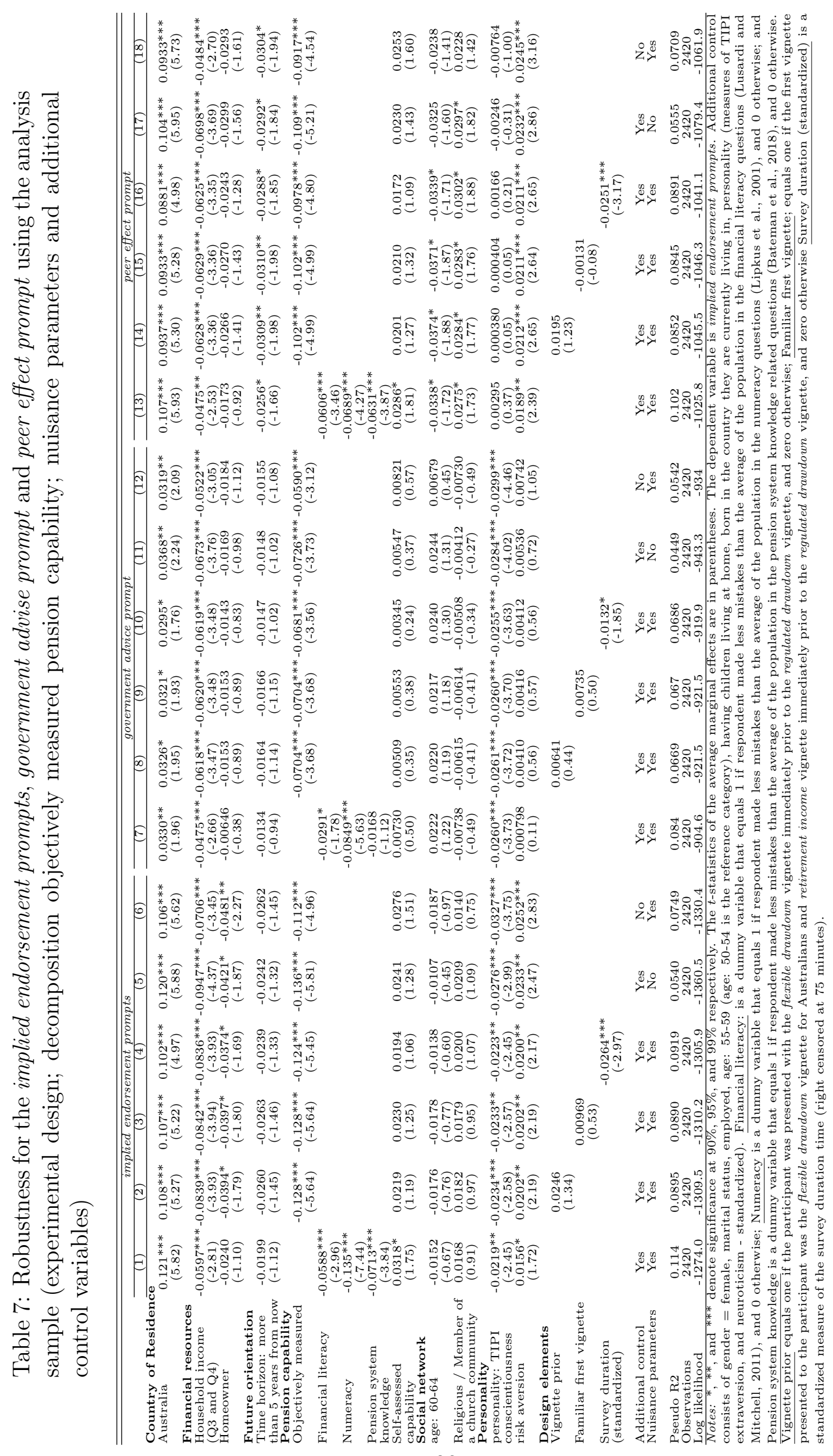


variable is not significant and that our results are robust to the first vignette seen in the first part of the experimental task.

Third, another confounding factor might be cognitive exhaustion. To control for this, we include the variable survey duration (standardized) that captures the participants' total survey response time. Note that individuals were not required to complete the survey in a fixed period of time - although in the Australian version they were informed that the survey would take approximately 25 minutes. ${ }^{24}$ Hence, our distribution of the survey response time is initially skewed towards (very) long response times. To address the possibility that the estimate for this variable is driven by these outliers, we cut participants who took more than 75 minutes to complete the survey. This affects 121 out of 983 Australian participants and 298 out of 1437 Dutch participants. The estimation results for the main variables of interest are unaffected by the inclusion of this proxy for cognitive exhaustion (see Table 7, columns (4), (10), and (16)). However, this proxy for cognitive exhaustion was typically statistically significant at conventional levels. The statistical negative parameter implies that participants who took more time to answer the survey were less likely to find the implied endorsement savings motive important. This could indicate that they do not suffer from cognitive exhaustion, but take the time to make a thoughtful choice. We interpret this as evidence against the conjecture that cognitive exhaustion affected our results, as otherwise we would have expected a similar effect size between the different prompts.

\subsubsection{Sensitivity to additional controls and nuisance parameters}

Finally, to assess whether our results were robust to the inclusion of the nuisance parameters and additional control variables, we present the marginal effects of the re-estimations without these variables in columns (5) and (6), (11) and (12) and (17) and (18) of Table 7.

For both the government advice prompt and the peer effect prompt we observe that the inclusion of the nuisance parameters does enhance the fit of the model. However, their inclusion does not affect the interpretation and it only slightly reduces the significance of the variables of interest.

\section{Conclusion}

In this paper we design and implement an online experimental survey to investigate the role that nudges - specifically implied endorsement, implicit government advice and social norm comparisons - could play in influencing retirement spending patterns. We investigate whether people are influenced by government regulated withdrawals from their pension wealth when making spending decisions, whether they perceive such regulations as implicit advice from the government or peers (a

\footnotetext{
${ }^{24}$ For example, a participant could start answering the survey for 30 minutes, then decide to close the browser and finish the survey in an additional 30 minutes a day later. This would be recorded as a survey duration of $1500\left(=30+30+24^{*} 60\right)$ minutes.
} 
social norm comparison) and whether the nudge actually influences the vulnerable groups it is designed to target.

Our experimental set-up uses two vignettes to present short descriptions of hypothetical retiree households with a given income similar to the state pension level, accrued retirement savings and an expectation to be in good health at age 70 . One vignette allows flexibility of drawdown (the flexible drawdown vignette), while a subsequent vignette includes a regulated drawdown from pension wealth set by government (the regulated drawdown vignette). For both vignettes, participants are asked to advise a hypothetical retiree household on a spending pattern and rank the importance of a set of saving motives consistent with that spending (and saving) advice. This design enables us to compare stated retirement spending and saving behaviour (while simultaneously ranking motivations for such behaviour) with, and in the absence of, an implied endorsement nudge (i.e., the regulated drawdown from pension wealth).

Our key findings can be summarized as follows. First, we find that the nudge we implement is effective, with over $30 \%$ of the Australian participants and just under $30 \%$ of the Dutch participants changing their preferred spending pattern as a result of the "implied endorsement". Second, we find that for the Dutch, the implied endorsement nudge is more effective when communicated as "what most people do" (the peer effect prompt). However, Australians in the sample are more likely to react when the implied endorsement nudge is communicated as "government knows best" (the government advice prompt). Third, we find the implied endorsement nudge conveyed by the regulated drawdown requirement to have greater impact on the more vulnerable participants in our sample, specifically those with fewer financial resources, lower (objectively measured) financial capability and a lower tendency for future financial planning. This indicates that the nudge was appropriately targeted to those less able to make welfare enhancing choices. However, the more conscientious are influenced less, suggesting that they could be more suspicious of the motive for a government regulated drawdown.

Finally, we find that peer effects, in terms of following the implied endorsement nudge, are stronger for risk averse individuals and those with a social network. This suggests that who are more risk averse have a higher tendency to compare with peers and therefore the spending/saving motive which emphasizes "what most people do" is more important to them.

Our findings have several important implications for pension policy design.

- First, despite the widespread introduction of DC pension arrangements, policy design has tended to focus on the accumulation phase. Few countries have considered how to approach the decumulation of pension assets. Even in Australia, which was one of the first to adopt mandatory DC arrangements, the prescription was limited to the coverage and size of contributions. Our results provide evidence for an alternative policy tool (i.e., regulated drawdown of pension wealth) to complement the standard options of flexible drawdowns and mandatory annuitization. 
- Second, there is emerging evidence that in the case of both drawdown flexibility and mandatory annuitization, current retirees draw down their pension assets far slower than suggested by standard lifecycle models and that even those at the lower end of the income and wealth distribution continue to accumulate assets in retirement (e.g., Asher et al., 2017, Dynan et al., 2004, and Van Ooijen et al., 2015). Our results show that a government regulated drawdown requirement could act as implied endorsement for spending patterns in retirement. Where appropriately set, it could ensure that retirees experience a standard of living in retirement which is consistent with the pension wealth accumulated during their working years.

- Finally, given the stickiness of spending patterns to regulated drawdown rule, particularly for the less financially capable and those with lower financial resources, extreme care would need to be taken in setting the drawdown rule.

Overall, we have provided evidence for the role of a government regulated drawdown of pension wealth as implied endorsement for spending patterns in retirement. Furthermore, we show that Dutch respond more where the implied endorsement is framed in terms of "what most people do" while Australians are more likely to respond to the suggestion that the implied endorsement is "implicit government advice". However, we do not discount the fact that slower than expected drawdown in retirement may be due to precautionary saving for unexpected and late in life health and aged care expenses and/or bequest intentions. As such we would advocate that governments and pension funds invest in education and/or financial guidance programs to increase awareness of likely financial and health risks in retirement as well as available sources of public and private support. 


\section{References}

Agnew, J. R., Bateman, H., and Thorp, S. (2013). Financial Literacy and Retirement Planning in Australia. Numeracy, 6(2):1-25.

Agnew, J. R. and Szykman, L. R. (2005). Asset allocation and information overload: The influence of information display, asset choice, and investor experience. The Journal of Behavioral Finance, 6(2):57-70.

Alonso-García, J., Bateman, H., Bonekamp, J., van Soest, A., and Stevens, R. (2018). Saving Preferences After Retirement. Available at: http://dx.doi.org/10.2139/ssrn.3184043.

APRA (2017). Annual Superannuation Bulletin. Available at: http://www.apra.gov.au/Super/Publications/Pages/annual-superannuationpublication.aspx.

Asher, A., Meyricke, R., Thorp, S., and Wu, S. (2017). Age pensioner decumulation: Responses to incentives, uncertainty and family need. Australian Journal of Management, 42(4):583-607.

Barberis, N. (2018). Richard Thaler and the Rise of Behavioral Economics. The Scandinavian Journal of Economics, 120(3).

Bateman, H., Deetlefs, J., Dobrescu, L. I., Newell, B. R., Ortmann, A., and Thorp, S. (2014). Just Interested or Getting Involved? An Analysis of Superannuation Attitudes and Actions. Economic Record, 90(289):160-178.

Bateman, H., Eckert, C., Iskhakov, F., Louviere, J., Satchell, S., and Thorp, S. (2018). Individual Capability and Effort in Retirement Benefit Choice. Journal of Risk and Insurance, 85(2):483-512.

Benartzi, S., Beshears, J., Milkman, K. L., Sunstein, C. R., Thaler, R. H., Shankar, M., Tucker-Ray, W., Congdon, W. J., and Galing, S. (2017). Should Governments Invest More in Nudging? Psychological Science, 28(8):1041-1055.

Benartzi, S., Previtero, A., and Thaler, R. H. (2011). Annuitization Puzzles. The Journal of Economic Perspectives, 25(4):143-164.

Benhassine, N., Devoto, F., Duflo, E., Dupas, P., and Pouliquen, V. (2015). Turning a Shove into a Nudge? A "Labeled Cash Transfer" for Education. American Economic Journal: Economic Policy, 7(3):86-125.

Beshears, J., Choi, J. J., Laibson, D., Madrian, B. C., and Milkman, K. L. (2015). The Effect of Providing Peer Information on Retirement Savings Decisions. The Journal of Finance, 70(3):1161-1201.

Beshears, J., Choi, J. J., Laibson, D., Madrian, B. C., and Wang, S. Y. (2016). Who Is Easier to Nudge? (Working Paper). Available at: https://scholar.harvard.edu/laibson/publications/who-easier-nudge. 
Breza, E. and Chandrasekhar, A. G. (2019). Social Networks, Reputation, and Commitment: Evidence From a Savings Monitors Experiment. Econometrica, 87(1):175-216.

Brown, J. R., Ivković, Z., Smith, P. A., and Weisbenner, S. (2008). Neighbors matter: Causal community effects and stock market participation. The Journal of Finance, 63(3):1509-1531.

Bütler, M. and Teppa, F. (2007). The choice between an annuity and a lump sum: Results from Swiss pension funds. Journal of Public Economics, 91(10):1944-1966.

Cameron, A. C. and Trivedi, P. K. (2005). Microeconometrics: Methods and Applications. Cambridge University Press.

Canada Revenue Agency (2017). Minimum withdrawal factors for registered retirement income funds. Retrieved from: http://www.craarc.gc.ca/gncy/bdgt/2015/qa02-eng.html.

Chetty, R., Friedman, J. N., Leth-Petersen, S., Nielsen, T. H., and Olsen, T. (2014). Active vs. Passive Decisions and Crowd-Out in Retirement Savings Accounts: Evidence from Denmark. The Quarterly Journal of Economics, 129(3):1141-1219.

Choi, J. J., Laibson, D., Madrian, B. C., and Metrick, A. (2002). Defined Contribution Pensions: Plan Rules, Participant Choices, and the Path of Least Resistance. Tax Policy and the Economy, 16:67-113.

Choi, J. J., Laibson, D., Madrian, B. C., and Metrick, A. (2004). For Better or for Worse: Default Effects and 401(k) Savings Behavior. In Wise, D. A., editor, Perspectives on the Economics of Aging, pages 81-126. University of Chicago Press.

Choi, J. J., Laibson, D. I., and Madrian, B. C. (2005). Are Empowerment and Education Enough? Underdiversification in 401(k) Plans. Brookings Papers on Economic Activity, 2005(2):151-213.

De Nardi, M., French, E., and Jones, J. B. (2016). Savings After Retirement: A Survey. Annual Review of Economics, 8(1):177-204.

Dinner, I., Johnson, E. J., Goldstein, D. G., and Liu, K. (2011). Partitioning default effects: Why people choose not to choose. Journal of Experimental Psychology: Applied, 17(4):332.

Dobrescu, L. I., Fan, X., Bateman, H., Newell, B. R., Ortmann, A., and Thorp, S. (2018). Retirement Savings: A Tale of Decisions and Defaults. The Economic Journal, 128(610):1047-1094.

Dohmen, T., Falk, A., Huffman, D., Sunde, U., Schupp, J., and Wagner, G. G. (2011). Individual risk attitudes: Measurement, determinants, and behavioral consequences. Journal of the European Economic Association, 9(3):522-550. 
Duflo, E. and Saez, E. (2002). Participation and investment decisions in a retirement plan: The influence of colleagues' choices. Journal of Public Economics, 85(1):121-148.

Duflo, E. and Saez, E. (2003). The Role of Information and Social Interactions in Retirement Plan Decisions: Evidence from a Randomized Experiment. Quarterly Journal of Economics, 118(3):815-843.

Dynan, K. E., Skinner, J., and Zeldes, S. P. (2004). Do the Rich Save More? Journal of Political Economy, 112(2):397-444.

Euwals, R., Knoef, M., and Van Vuuren, D. (2011). The trend in female labour force participation: what can be expected for the future? Empirical Economics, 40(3):729-753.

Fisher, P. J. and Montalto, C. P. (2011). Loss Aversion and Saving Behavior: Evidence from the 2007 U.S. Survey of Consumer Finances. Journal of Family and Economic Issues, 32(1):4-14.

Fry, T., Heaney, R., and McKeown, W. (2007). Will investors change their superannuation fund given the choice? Accounting 85 Finance, 47(2):267-283.

Gallagher, P. (2012). Treasury measurement of retirement income adequacy. Presentation to FEAL Pre-Forum Discussion, February 9, 2011.

Gerrans, P. and Clark-Murphy, M. (2004). Gender differences in retirement savings decisions. Journal of Pension Economics \&f Finance, 3(2):145-164.

Gosling, S. D., Rentfrow, P. J., and Swann, W. B. (2003). A very brief measure of the Big-Five personality domains. Journal of Research in Personality, 37(6):504-528.

Griffith, R., von Hinke, S., and Smith, S. (2018). Getting a healthy start: The effectiveness of targeted benefits for improving dietary choices. Journal of Health Economics, 58:176-187.

Hallsworth, M., List, J. A., Metcalfe, R. D., and Vlaev, I. (2017). The behavioralist as tax collector: Using natural field experiments to enhance tax compliance. Journal of Public Economics, 148:14-31.

Hedesstrom, T. M., Svedsater, H., and Garling, T. (2004). Identifying heuristic choice rules in the Swedish premium pension scheme. The Journal of Behavioral Finance, 5(1):32-42.

Internal Revenue Service (2017). Retirement Topics - Required Minimum Distributions (RMDs). Retrieved from: https://www.irs.gov/retirementplans/retirement-plans-faqs-regarding-required-minimum-distributions.

Knoef, M., Been, J., Alessie, R., Caminada, K., Goudswaard, K., and Kalwij, A. (2016). Measuring retirement savings adequacy: developing a multi-pillar approach in the Netherlands. Journal of Pension Economics $\mathscr{G}$ Finance, 15(1):5589. 
Lehner, M., Mont, O., and Heiskanen, E. (2016). Nudging - A promising tool for sustainable consumption behaviour? Journal of Cleaner Production, 134:166-177.

Lipkus, I. M., Samsa, G., and Rimer, B. K. (2001). General Performance on a Numeracy Scale among Highly Educated Samples. Medical Decision Making, 21(1):37-44.

Louviere, J. J., Hensher, D. A., and Swait, J. D. (2000). Stated Choice Methods: Analysis and Applications. Cambridge University Press.

Love, D. A., Palumbo, M. G., and Smith, P. A. (2009). The trajectory of wealth in retirement. Journal of Public Economics, 93(1-2):191-208.

Lusardi, A. and Mitchell, O. S. (2011). Financial literacy around the world: an overview. Journal of Pension Economics \& Finance, 10(4):497-508.

Madrian, B. C. and Shea, D. F. (2001). The power of suggestion: Inertia in 401(k) participation and savings behavior. The Quarterly Journal of Economics, 116(4):1149-1187.

Mercer (2018). Melbourne Mercer Global Pension Index. Australian Centre for Financial Studies, Melbourne.

MoneySmart (2016). Account-based pensions. Retrieved from: https://www.moneysmart.gov.au/superannuation-and-retirement/incomesources-in-retirement/income-from-super/account-based-pensions.

OECD (2015). Pensions at a Glance 2015 - OECD and G20 indicators. OECD Publishing, Paris.

Sunstein, C. R. (2013). Deciding by default. University of Pennsylvania Law Review, $162(1): 1-57$.

Sunstein, C. R. (2014). Nudging: a very short guide. Journal of Consumer Policy, $37(4): 583-588$.

Thaler, R. H. and Sunstein, C. R. (2008). Nudge: Improving Decisions about Health, Wealth, and Happiness. New Haven, CT: Yale University Press.

Van Ooijen, R., Alessie, R., and Kalwij, A. (2015). Saving behavior and portfolio choice after retirement. De Economist, 163(3):353-404.

Wrzus, C., Hänel, M., Wagner, J., and Neyer, F. J. (2013). Social network changes and life events across the life span: A meta-analysis. Psychological Bulletin, 139(1):53-80. 


\section{Appendix A Dutch and the Australian pension systems}

\section{Dutch pension system}

The first pillar of the Dutch pension system is a Beveridge type public pension which provides a flat-rate pension to all residents. Its level is linked to the minimum wage and payments are indexed to wages growth. The eligibility age is increasing from 65 years to 67 years over the period 2013 to 2021, and thereafter commencement age will be linked to the remaining life expectancy at age 65 .

The second pillar of the Dutch pension system comprises occupational pension schemes, which are typically part of the labour contract negotiated between unions and employers in collective labour agreements. Employees are obliged to participate and have limited choice in the accrual of pensions. The most popular schemes are defined benefits arrangements where pension accrual and information communication is as a (replacement of) income. Despite being referred to as a defined benefit country, employers have progressively withdrawn from their role as sponsors, leaving the participant's to bear investment and longevity risk. Indexation of occupational pensions is conditional on the funding ratio of the fund, and nominal pension cuts are possible. The typical pension product is a life annuity plus a $70 \%$ reversionary annuity for a surviving spouse. There is limited, but increasing, choice in pension plans. On a plan by plan basis, participants can choose to retire early and take the annuity income earlier, and to change the payment schedule to start with higher or lower income than the scheduled amount (reverting to lower/higher income in later years). Around $90 \%$ of workers are covered by the second pillar pensions. Most pension plans aim for a gross replacement rate of $70 \%$ of average career salary (including first pillar pension benefits) for an individual with 40 years of (full-time) employment (Knoef et al., 2016).

\section{Australian pension system}

The first pillar in the Australian pension system is also a Beveridge type public system which provides a means-tested flat pension to all residents (known as the Age Pension). The level (for a single pension) is set at $27 \%$ of male average earnings and payments are indexed to the maximum of price and wage inflation. The meanstest is comprehensively defined with both an income test and an asset test, but excludes housing wealth. The eligibility age is increasing from 65 years to 67 years between 2017 and 2023.

The second pillar in the Australian pension system is an earnings-related, defined contribution scheme known as the "superannuation guarantee". Employers are required to contribute at least $9.5 \%$ of an employee's income into a pension account. Although participation is mandatory, fund members have plethora of choice. They can choose the pension provider, the pension plan, whether to make voluntary contributions (in excess of the minimum 9.5\%) and the investment portfolio. In retirement, subject to an access age of 60 , the participant can choose at which age to commence decumulation and in what form benefits are taken: a lump sum and/or a phased withdrawal product and/or an annuity. Most people take non-annuitized 
phased withdrawal products at retirement. Under current policy settings a person on average weekly earnings working for 40 years could expect a replacement rate of 65-70\% from an annuitized superannuation accumulation and a part Age Pension (Gallagher, 2012).

\title{
Appendix B Summary of the vignette design
}

This appendix summarizes the key features of the vignette design, including the base text for each vignette (Figure B.1) and key screenshots.

Figure B.1: Base text for each vignette

\begin{abstract}
The household consists of two individuals currently 65 years old who have just retired. Both are in good health and expect to stay so at least until they reach the age of 70 .

Each household has a net of tax lifetime income of [INSERT INCOME] and their wealth at retirement is [INSERT WEALTH]. The household owns the house they live in, without a mortgage. They don't want to move or sell their house. If one member of the household dies, the survivor will receive less income but also spend less. The reduction in income is roughly equivalent to the reduction in spending.

At retirement the household has to plan how much they expect to save and spend, based on their income and current wealth. The following table shows five different spending plans together with income and wealth at different ages (if they survive). If their wealth is exhausted then the household has to adapt their spending to their income. [REGULATED DRAWDOWN or not]
\end{abstract}

Finally, you can assume that prices do not change over time.

Part A:

What spending plan do you advise the household to choose, based on your preferences?

$<<$ Show five different SPENDING PLANS, accompanied by a reminder of annual and fortnightly/monthly income, and information about remaining wealth at ages $65,75,85,95>>$

Part B:

Below you see five possible reasons to choose a specific spending plan.

Please indicate which reason is the most important for this household, based on your own preferences, and which saving motive is the least important. Then indicate which saving motive is the 2nd most important and the 2nd least important. $<<$ Show five different SAVING $\overline{\text { MOTIVES (subject to category restrictions) }>>}$ 
Figure B.2: Screenshot of task 1 (Part A) for the flexible drawdown vignette for the lowest income group in the Australian version of the survey.

\section{Choice Set 2 of 8}

\section{Part A}

Below we describe the financial situation of a hypothetical household. This household consists of two individuals currently 65 years old who have just retired. Both are in good health and expect to stay so at least until they reach the age of 70 .

Each household has a net of tax lifetime income of $\$ 31,450$ per annum $(\$ 1.210$ fortnightly) and their wealth at retirement is $\$ 291,000$. The household owns the house they live in, without a mortgage. They don't want to move or sell their house. If one member of the household dies, the survivor will receive less income but also spend less. The reduction in income is roughly equivalent to the reduction in spending.

At retirement the household has to plan how much they expect to save and spend, based on their income and current wealth. The following table shows five different spending plans together with the income and wealth at different ages (if they survive). If their wealth is exhausted then the household has to adapt their spending to their income.

Finally, you can assume that the prices don't change over time

What plan do you advise the household to choose, based on your own preferences?

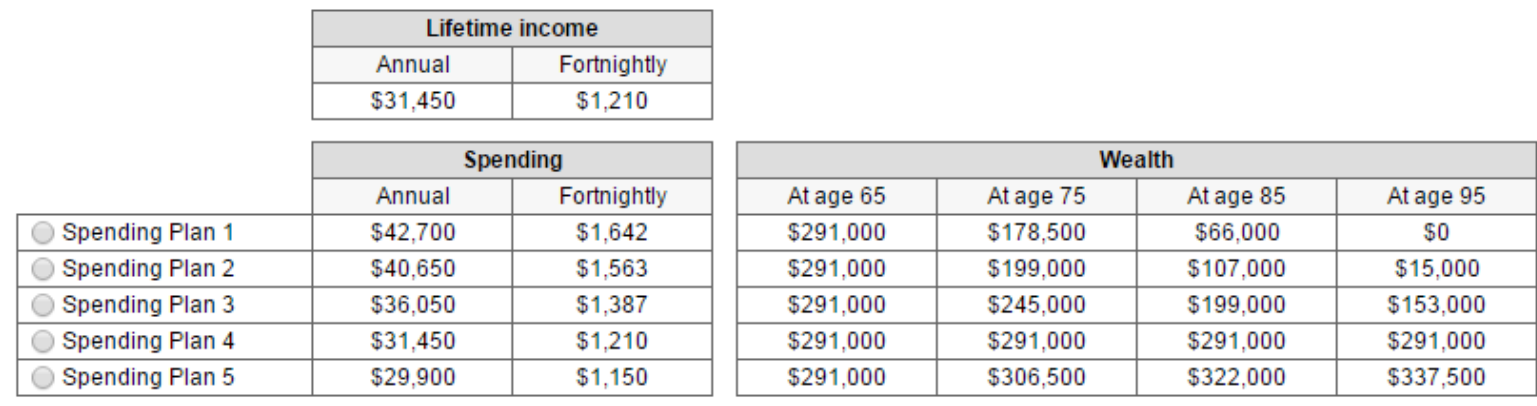

Figure B.3: Screenshot of task 2 (Part B) in the flexible drawdown vignette for the lowest income group in the Australian version of the survey.

\section{Choice Set 2 of 8}

\section{Part B}

You would advise the household to choose the following spending plan.

\begin{tabular}{|c|c|}
\hline \multicolumn{2}{|c|}{ Lifetime income } \\
\hline Annual & Fortnightly \\
\hline$\$ 31,450$ & $\$ 1,210$ \\
\hline
\end{tabular}

\begin{tabular}{|l|c|c|}
\cline { 2 - 3 } \multicolumn{1}{c|}{} & \multicolumn{2}{c|}{ Spending } \\
\cline { 2 - 3 } \multicolumn{1}{c|}{} & Annual & Fortnightly \\
\hline Spending Plan 1 & $\$ 42,700$ & $\$ 1,642$ \\
\hline
\end{tabular}

\begin{tabular}{|c|c|c|c|}
\hline \multicolumn{4}{|c|}{ Wealth } \\
\hline At age 65 & At age 75 & At age 85 & At age 95 \\
\hline$\$ 291,000$ & $\$ 178,500$ & $\$ 66,000$ & $\$ 0$ \\
\hline
\end{tabular}

Below you see five possible reasons to choose a specific spending plan.

Please indicate which reason is the most important for this household, based on your own preferences, and which saving motive is the least important Then indicate which saving motive is the 2 nd most important and 2nd least important

The household.

\begin{tabular}{|c|c|c|c|c|}
\hline $\begin{array}{c}\text { MOST } \\
\text { important } \\
\text { reason to save }\end{array}$ & \begin{tabular}{|c|}
$\begin{array}{c}\text { 2nd MOST } \\
\text { important } \\
\text { reason to save }\end{array}$ \\
\end{tabular} & Reasons to save & 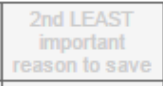 & \begin{tabular}{|c|} 
LEAST \\
important \\
reason to save
\end{tabular} \\
\hline$\bigcirc$ & O & wants to ensure that they have enough cash on hand at any time & O & O \\
\hline$\bigcirc$ & O & wants to ensure that they are able to enjoy life now as well as later. & 0 & O \\
\hline O & 0 & wants to ensure that they have enough money to have peace of mind. & 0 & O \\
\hline ○ & O & wants to ensure that they will not outlive their wealth. & O & $\bigcirc$ \\
\hline$\bigcirc$ & 0 & $\begin{array}{c}\text { wants to ensure that they will be able to finance unforeseen health and aged care } \\
\text { expenditures. }\end{array}$ & 0 & 0 \\
\hline
\end{tabular}


Figure B.4: Screenshot of task 1 (Part A) for the regulated drawdown vignette for the lowest income group in the Australian version of the survey.

\section{Choice Set 4 of 8}

\section{Part A}

Below we describe the financial situation of a hypothetical household. This household consists of two individuals currently 65 years old who have just retired. Both are in good health and expect to stay so at least until they reach the age of 70 .

Each household has a net of tax lifetime income of $\$ 31,450$ per annum (\$1,210 fortnightly) and their wealth at retirement is $\$ 291,000$. The household owns the house they live in, without a mortgage. They don't want to move or sell their house. If one member of the household dies, the survivor will receive less income but also spend less. The reduction in income is roughly equivalent to the reduction in spending.

At retirement the household has to plan how much they expect to save and spend, based on their income and current wealth. The following table shows five different spending plans together with the income and wealth at different ages (if they survive). If their wealth is exhausted then the household has to adapt their spending to their income. Government regulations require that they withdraw a part of their wealth each year to supplement their income. This corresponds to $\$ 14,550$ yearly. The household is not obliged to (fully) spend this supplementary income.

Finally, you can assume that the prices don't change over time.

What plan do you advise the household to choose, based on your own preferences?

\begin{tabular}{|c|c|c|c|c|c|c|}
\hline & \multirow{2}{*}{\multicolumn{2}{|c|}{ Lifetime income }} & & & & \\
\hline & & & & & & \\
\hline & Annual & Fortnightly & & & & \\
\hline & $\$ 31,450$ & $\$ 1,210$ & & & & \\
\hline & \multicolumn{2}{|c|}{ Spending } & \multicolumn{4}{|c|}{ Wealth } \\
\hline & Annual & Fortnightly & At age 65 & At age 75 & At age 85 & At age 95 \\
\hline Spending Plan 1 & $\$ 42,700$ & $\$ 1,642$ & $\$ 291,000$ & $\$ 178,500$ & $\$ 66,000$ & $\$ 0$ \\
\hline Spending Plan 2 & $\$ 40,650$ & $\$ 1,563$ & $\$ 291,000$ & $\$ 199,000$ & $\$ 107,000$ & $\$ 15,000$ \\
\hline Spending Plan 3 & $\$ 36,050$ & $\$ 1,387$ & $\$ 291,000$ & $\$ 245,000$ & $\$ 199,000$ & $\$ 153,000$ \\
\hline Spending Plan 4 & $\$ 31,450$ & $\$ 1,210$ & $\$ 291,000$ & $\$ 291,000$ & $\$ 291,000$ & $\$ 291,000$ \\
\hline Spending Plan 5 & $\$ 29,900$ & $\$ 1,150$ & $\$ 291,000$ & $\$ 306,500$ & $\$ 322,000$ & $\$ 337,500$ \\
\hline
\end{tabular}

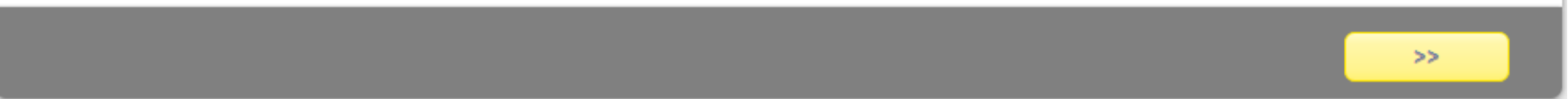

Figure B.5: Screenshot of task 2 (Part B) for the regulated drawdown vignette for the lowest income group in the Australian version of the survey.

\section{Choice Set 4 of 8}

\section{Part B}

You would advise the household to choose the following spending plan.

\begin{tabular}{|c|c|c|}
\cline { 2 - 2 } \multicolumn{1}{c|}{} & \multicolumn{2}{c|}{ Lifetime income } \\
\cline { 2 - 3 } & Annual & Fortnightly \\
\hline$\$ 31,450$ & $\$ 1,210$ \\
\cline { 2 - 3 } \multicolumn{2}{c|}{ Spending } \\
\cline { 2 - 3 } \multicolumn{1}{c|}{} & Annual & Fortnightly \\
\hline Spending Plan 2 & $\$ 40,650$ & $\$ 1,563$ \\
\hline
\end{tabular}

\begin{tabular}{|c|c|c|c|}
\hline \multicolumn{4}{|c|}{ Wealth } \\
\hline At age 65 & At age 75 & At age 85 & At age 95 \\
\hline$\$ 291,000$ & $\$ 199,000$ & $\$ 107,000$ & $\$ 15,000$ \\
\hline
\end{tabular}

Below you see five possible reasons to choose a specific spending plan.

Please indicate which reason is the most important for this household, based on your own preferences, and which saving motive is the least important Then indicate which saving motive is the 2 nd most important and 2 nd least important

The household.

\begin{tabular}{|c|c|c|c|c|}
\hline $\begin{array}{c}\text { MOST } \\
\text { important } \\
\text { reason to save }\end{array}$ & \begin{tabular}{c|}
$\begin{array}{c}\text { 2nd MOST } \\
\text { important } \\
\text { reason to save }\end{array}$ \\
\end{tabular} & Reasons to save & \begin{tabular}{|c|} 
2nd LFAST \\
important \\
reason to save
\end{tabular} & $\begin{array}{c}\text { LEAST } \\
\text { important } \\
\text { reason to save }\end{array}$ \\
\hline 0 & 0 & $\begin{array}{l}\text { wants to stick to the withdrawal amounts suggested by the government as that is what } \\
\text { most people do. }\end{array}$ & 0 & 0 \\
\hline 0 & 0 & wants to ensure that they have enough money to have peace of mind. & 0 & 0 \\
\hline O & 0 & wants to ensure that they are able to enjoy life now as well as later. & 0 & ○ \\
\hline O & O & $\begin{array}{l}\text { wants to stick to the withdrawal amounts suggested by the government as the government } \\
\text { knows best. }\end{array}$ & 0 & O \\
\hline O & $\bigcirc$ & $\begin{array}{c}\begin{array}{c}\text { wants to ensure that they will be able to finance unforeseen health and aged care } \\
\text { expenditures. }\end{array}\end{array}$ & 0 & 0 \\
\hline
\end{tabular}


Spending from regulated retirement drawdowns: the role of implied endorsement

Supplemental material: Additional estimation results

October 17, 2019 


\section{S.1 Additional estimation results}

\section{S.1.1 Sensitivity to the definition of reduced sample}

The use of an ordinal variable for advised spending pattern limits the information on whether a participant would prefer to further increase or decrease his spending when he advises the highest or lowest spending pattern in the first vignette. This could lead to biased outcomes, as we might underestimate or overestimate the probabilities. Therefore, as a robustness check the Logit regressions are estimated reducing the sample by only the participants who advised in the flexible drawdown vignette the lowest or highest spending pattern, respectively. The results are presented in Table A.1 and Table A.2.

The result of this procedure shows that despite the slight variation in significance and size of the control variables, the interpretation of the results is robust to the alternative selection methods for constructing the sample.

\section{S.1.2 Sensitivity to the underlying distribution assumptions}

In general, the underlying distribution of the estimation procedure to analyse binary outcome variables hardly affects the resulting average marginal effects. This is a direct consequence the similar cumulative distribution functions for most of the (same) random variable. However, the tails of these distribution differ. Hence, as our estimation results for the importance of the prompts for implied endorsement (implied endorsement prompts, government advice prompt and peer effect prompt) are driven by a relative small number of individuals in our analysis sample, this potentially could affect our results. Therefore, we re-estimate the importance of the nudge for implied endorsement using a Probit model and using a Linear Probability Model (LPM) (see, for example, Cameron and Trivedi, 2005).

The result of this procedure for the variables implied endorsement prompts, government advice prompt and peer effect prompt are presented in Table A.3. We compare these results with the findings under the Logit specification presented in Table 6. Despite the slight variation in significance and size of the control variables, the interpretation of the results is robust to the alternative distributional assumptions for the Australian and the Dutch sample for the studied prompts.

\section{S.1.3 Explanation of the positive sign of self-assessed (pen- sion) capability}

We hypothesise that the positive effect of the self-assessed capability is due to participants who overestimate their capabilities. Therefore, we test what drives the positive effect for self-assessed capability by re-estimating the model using four indicator functions based on the objectively and subjectively measured pension capabilities combinations:

- (A00): Participants who know that they do not know [self-assessed $=0$ \& objectively measured $=0]$; 


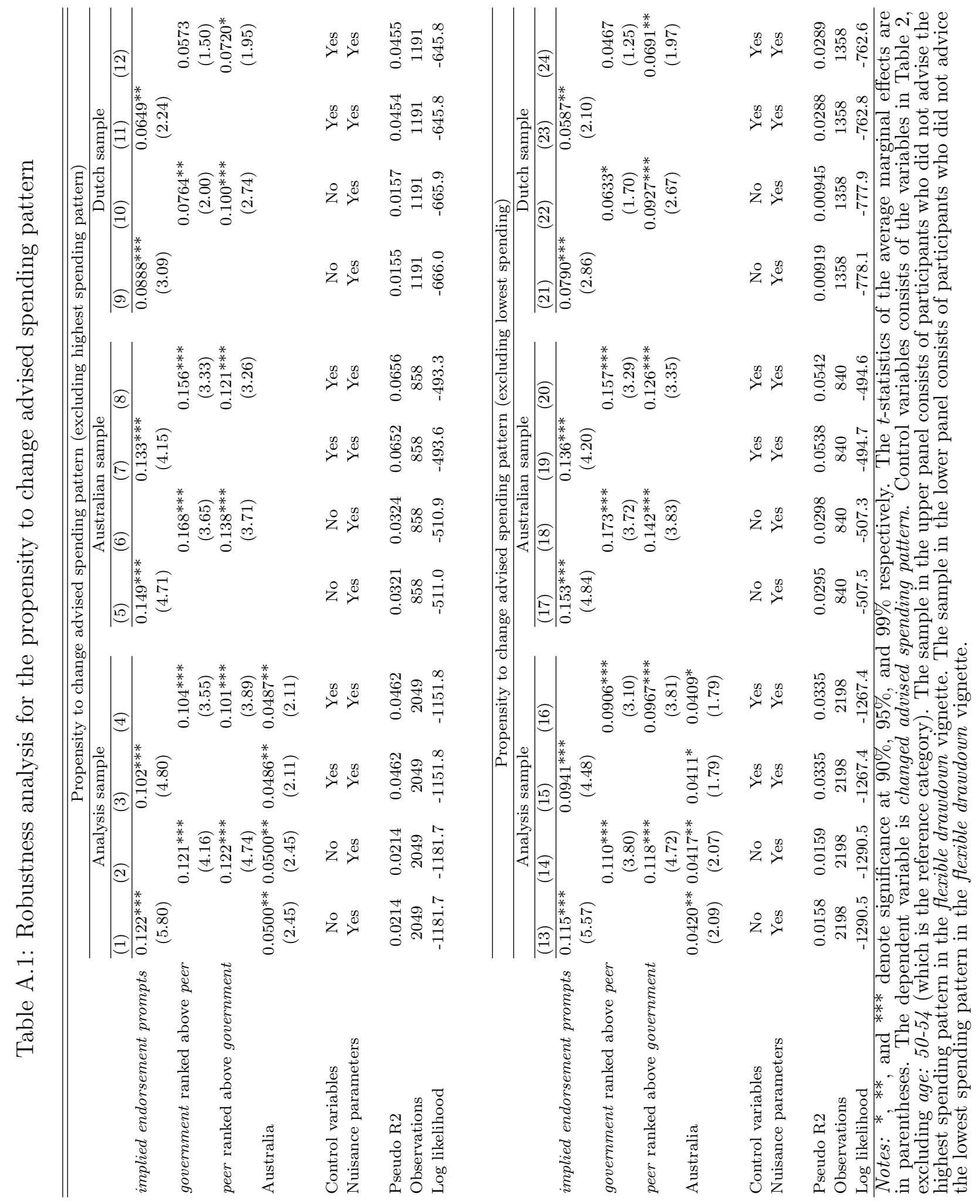




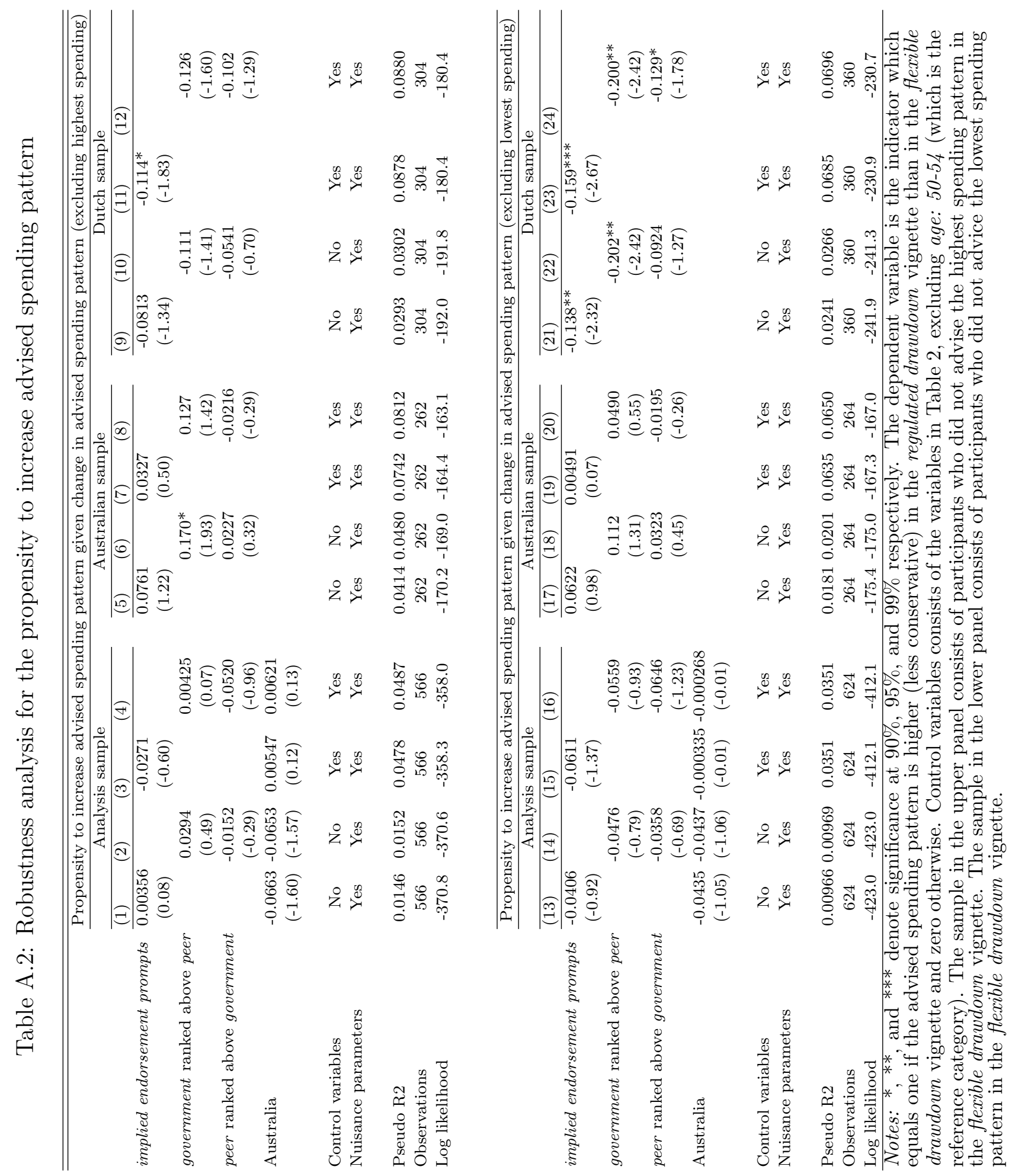




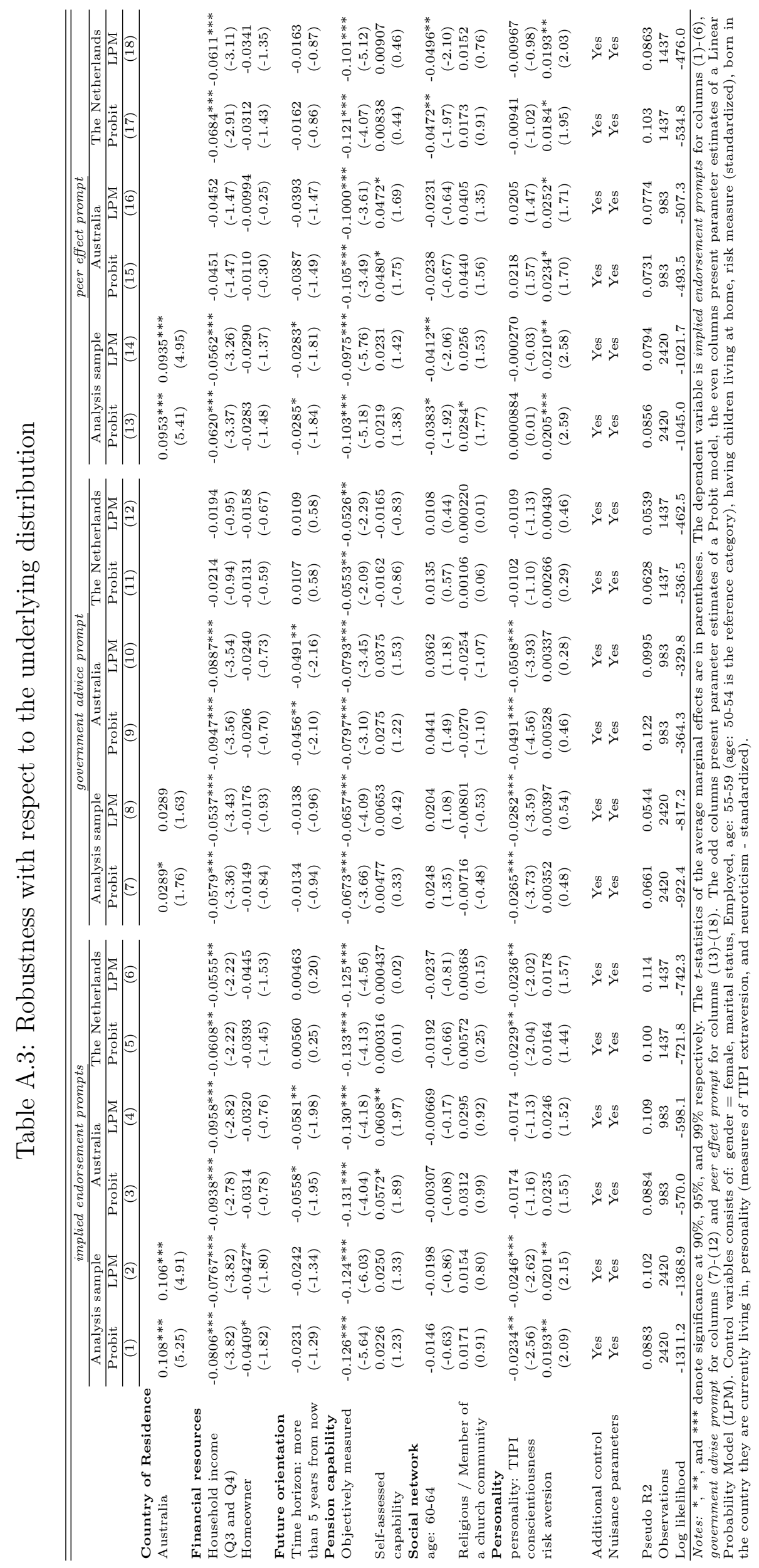


Table A.4: Share (\%) of participants that find the implied endorsement prompts important using the analysis sample.

\begin{tabular}{|c|c|c|c|c|}
\hline & $(\mathrm{A} 00)$ & (A10) & $(\mathrm{A} 01)$ & (A11) \\
\hline & $\begin{array}{l}{[\text { self-assessed }=0 \& \text { }} \\
\text { objectively measured }=0]\end{array}$ & $\begin{array}{l}{[\text { self-assessed }=1 \&} \\
\text { objectively measured }=0]\end{array}$ & $\begin{array}{l}{[\text { self-assessed }=0 \&} \\
\text { objectively measured }=1]\end{array}$ & $\begin{array}{l}{[\text { self-assessed }=1 \&} \\
\text { objectively measured }=1]\end{array}$ \\
\hline implied endorsement prompts & 30.7 & 30.7 & 17.4 & 21.5 \\
\hline government advice prompt & 16.0 & 15.3 & 9.6 & 9.4 \\
\hline peer effect prompt & 19.7 & 20.1 & 7.9 & 14.3 \\
\hline Observations & 929 & 900 & 178 & 413 \\
\hline
\end{tabular}

- (A10): Participants who think they know, but they do not - i.e. these are overconfident [self-assessed $=1 \&$ objectively measured $=0$ ];

- (A01): Participants who do not know that they know [self-assessed $=0$ \& objectively measured $=0]$ and;

- (A11): Participants who know that they know [objectively measured $=1 \&$ selfassessed $=0]$.

Note that each participant can belong to exactly one of these four groups based on their own responses. The size of each group together with the share of the group that finds the implied endorsement prompts important can be found in Table A.4.

The result of the re-estimating procedure is presented in Table A.5. ${ }^{1}$ We can not reject the null hypothesis that the effect of (A10) - i.e. overconfident participants - is similar to (A00), whereas the likelihood of finding the prompts important significantly decreases for those with objectively measured pension capabilities equal to one. We interpret this result as evidence in favour of our conjecture that the positive effect of the self-assessed capability is due to participants who overestimate their capabilities. The difference between (A01) and (A11) is, although sizeable, generally not statistically significant at the $5 \%$ level. $^{2}$

The country difference in the effect of the self-assessed capability (cf. Table 6 in the main body of this paper) could relate to differences between countries with respect to their real world pension systems. In the Netherlands, the government mandates a lifelong retirement income payment and does not require a minimum withdrawal rate. However, in Australia, those purchasing phased withdrawal products are required to withdraw a minimum amount to be able to access tax concessions. Since Australians are more familiar with phased withdrawal strategies, overconfident individuals might be more inclined to think that they can manage their finances well enough to sustain a high spending level. Therefore, our experimental setting, and the familiarity of the Australian participants to it, might be driving the result of the overconfidence, and thereby indirectly and self-assessed, measure.

\footnotetext{
${ }^{1}$ The difference in the financial resources, social network, and future orientation related variables between the two estimations - Table 6 and Table A.5 - is negligible.

${ }^{2}$ The only exception is for the peer effect prompt using the analysis sample.
} 
Table A.5: Results for the importance of the "government advice" and "peer effect" prompts with objectively measured and self-assessed combinations. Average marginal effects based on Logit estimates

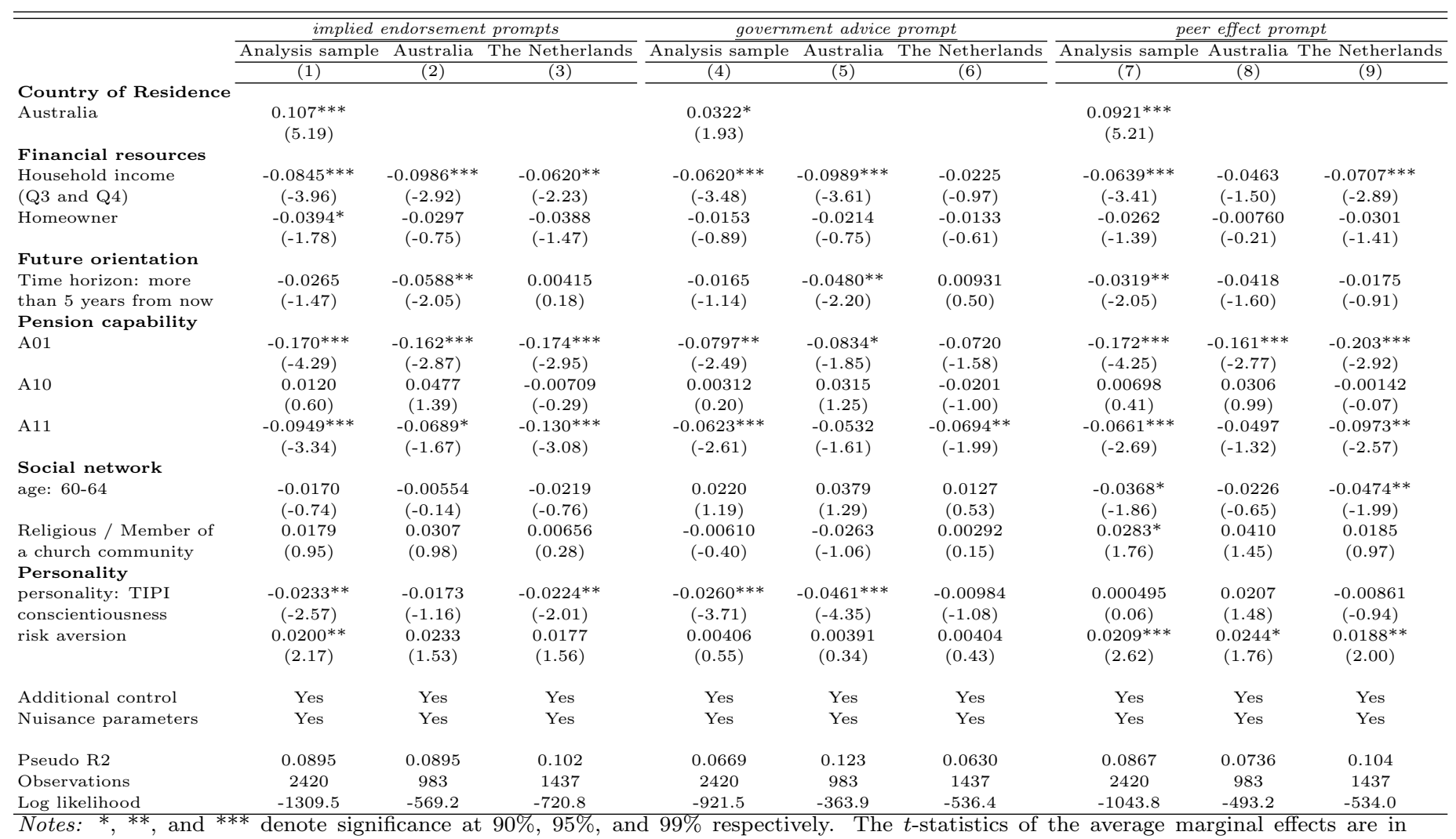

parentheses. The dependent variable is implied endorsement prompts for columns (1)-(6), government advise prompt for columns (7)-(12) and peer effect prompt for columns (13)-(18). Additional control consists of: gender = female, marital status, Employed, age: 55-59 (age: 50-54 is the reference category), having children living at home, born in the country they are currently living in, personality (measures of TIPI extraversion, and neuroticism - standardized). Pension capabilities consist of three measures. (A00): Participants who know that they do not know (reference category); (A10): Participants who think they know, but they do not - i.e. these are overconfident; (A01): Participants who do not know that they know; (A11) Participants who know that they know. 


\section{S.1.4 Country-specific robustness}

The country-robustness checks, as described in Section 4.3, are presented in Tables A.6 and A.7. 


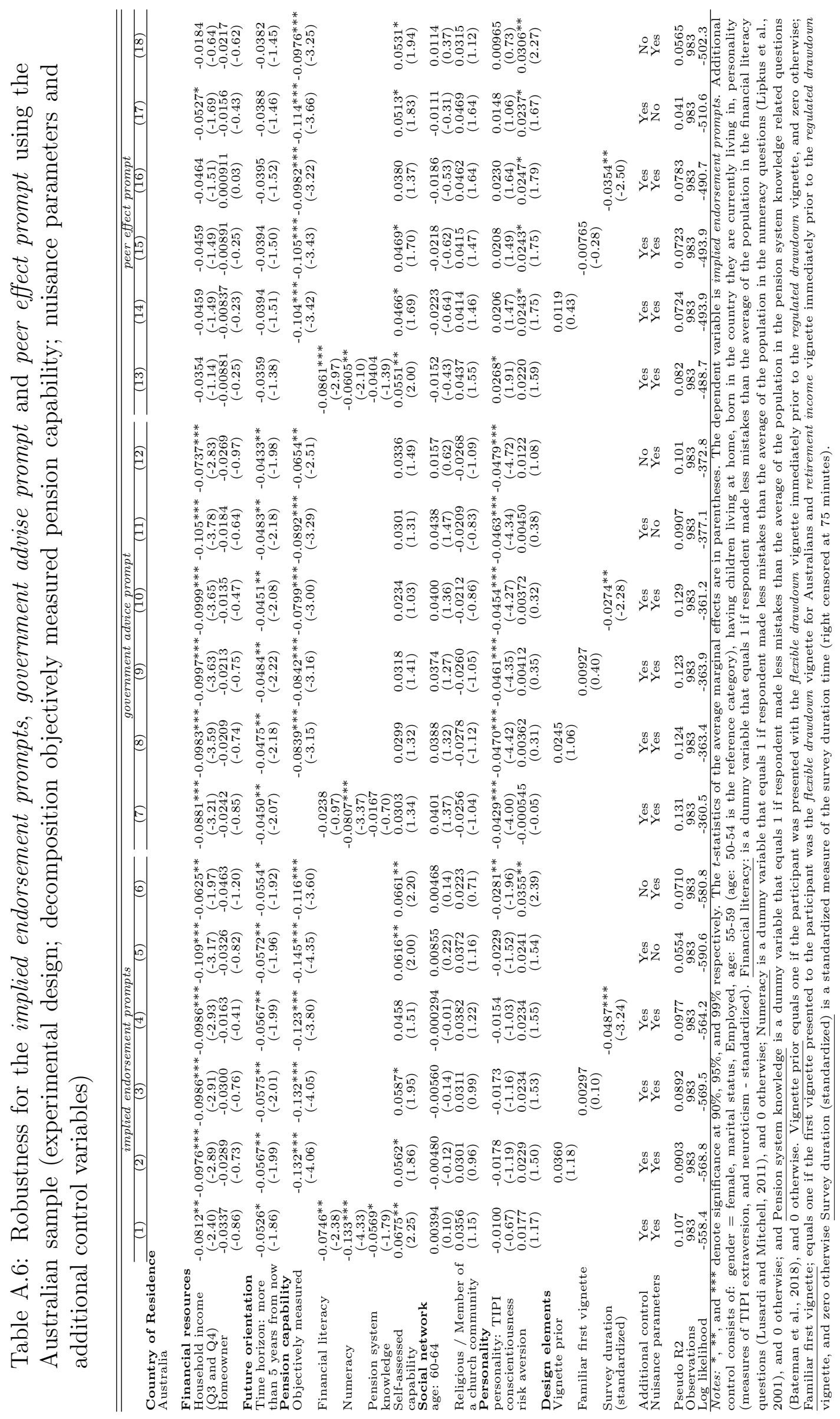




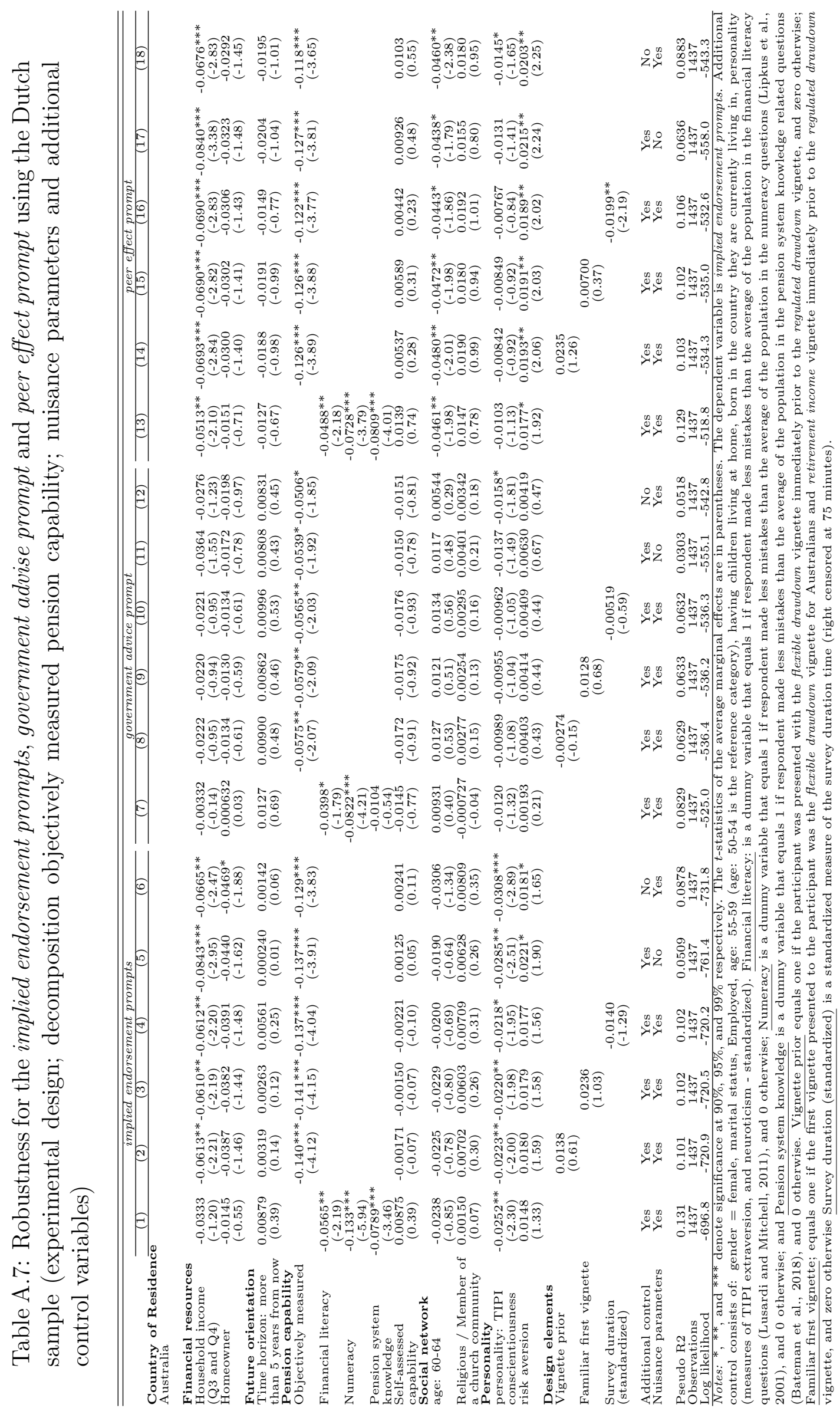




\section{References}

Bateman, H., Eckert, C., Iskhakov, F., Louviere, J., Satchell, S., and Thorp, S. (2018). Individual Capability and Effort in Retirement Benefit Choice. Journal of Risk and Insurance, 85(2):483-512.

Cameron, A. C. and Trivedi, P. K. (2005). Microeconometrics: Methods and Applications. Cambridge University Press.

Lipkus, I. M., Samsa, G., and Rimer, B. K. (2001). General Performance on a Numeracy Scale among Highly Educated Samples. Medical Decision Making, 21(1):37-44.

Lusardi, A. and Mitchell, O. S. (2011). Financial literacy around the world: an overview. Journal of Pension Economics \& Finance, 10(4):497-508. 